Pacific Northwest

National Laboratory

Operated by Battelle for the

U.S. Department of Energy

\title{
Carbon Tetrachloride and Chloroform Partition Coefficients Derived from Aqueous Desorption of Contaminated Hanford Sediments
}

\author{
R. G. Riley \\ J. E. Szecsody \\ D. S. Sklarew \\ A. V. Mitroshkov \\ C. F. Brown \\ C. J. Thompson \\ P. M. Gent
}

July 2005

Prepared for the U.S. Department of Energy under Contract DE-AC05-76RL01830 


\title{
DISCLAIMER
}

This report was prepared as an account of work sponsored by an agency of the United States Government. Neither the United States Government nor any agency thereof, nor Battelle Memorial Institute, nor any of their employees, makes any warranty, express or implied, or assumes any legal liability or responsibility for the accuracy, completeness, or usefulness of any information, apparatus, product, or process disclosed, or represents that its use would not infringe privately owned rights. Reference herein to any specific commercial product, process, or service by trade name, trademark, manufacturer, or otherwise does not necessarily constitute or imply its endorsement, recommendation, or favoring by the United States Government or any agency thereof, or Battelle Memorial Institute. The views and opinions of authors expressed herein do not necessarily state or reflect those of the United States Government or any agency thereof.

\author{
PACIFIC NORTHWEST NATIONAL LABORATORY \\ operated by \\ BATTELLE \\ for the
}

UNITED STATES DEPARTMENT OF ENERGY

under Contract DE-AC05-76RL01830

Printed in the United States of America

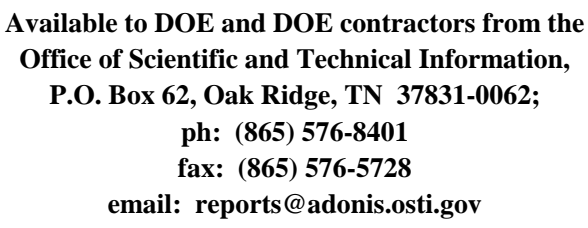

\footnotetext{
Available to the public from the National Technical Information Service, U.S. Department of Commerce, 5285 Port Royal Rd., Springfield, VA 22161 ph: (800) 553-6847 fax: (703) 605-6900

email: orders@ntis.fedworld.gov online ordering: http://www.ntis.gov/ordering.htm
} 


\section{Carbon Tetrachloride and Chloroform Partition Coefficients Derived from Aqueous Desorption of Contaminated Hanford Sediments}
R. G. Riley
J. E. Szecsody
D. S. Sklarew
A. V. Mitroshkov
C. F. Brown
P. M. Gent ${ }^{(a)}$
C. J. Thompson

July 2005

Prepared for

the U.S. Department of Energy

under Contract DE-AC05-76RL01830

Pacific Northwest National Laboratory

Richland, Washington 99352

(a) Fluor Hanford, Inc. 


\section{Summary}

Fluor Hanford, Inc. (FHI) has identified data needs important to locating, characterizing, and assessing the impact of carbon tetrachloride $\left(\mathrm{CCl}_{4}\right)$ contamination underlying the $200 \mathrm{West}$ Area on the Hanford Site. One need, which is described in this report, is to establish partition coefficients between gas, liquid, and solid phases for $\mathrm{CCl}_{4}$ based on contaminated sediments and to use such data to refine the fate and transport modeling performed to assess the impacts of the $200 \mathrm{West}$ Area $\mathrm{CCl}_{4}$ plume.

Researchers at PNNL determined $\mathrm{CCl}_{4}$ and chloroform $\left(\mathrm{CHCl}_{3}\right)$ groundwater/sediment partition coefficients ( $\mathrm{K}_{d}$ values) for contaminated aquifer sediments collected from borehole C3246 (299-W15-46) located in the 200 West Area adjacent to the 216-Z-9 trench. Having realistic values for this parameter is critical to predict future movement of $\mathrm{CCl}_{4}$ in groundwater from the $200 \mathrm{West}$ Area. It is best to obtain such values from contaminated sediments because the values will reflect the long sediment/contaminant contact times that are not possible to mimic in laboratory experiments. The $\mathrm{K}_{\mathrm{d}}$ values used in modeling $\mathrm{CCl}_{4}$ are crucial to more accurate estimation of whether compliance limits may be exceeded outside the Central Plateau waste management area.

$\mathrm{CCl}_{4}$ and $\mathrm{CHCl}_{3}$ partition coefficients for groundwater and sediment were determined in contaminated aquifer sediments of the Ringold Formation collected at depths in the range of 230 to 430 feet from the borehole 299-W15-46. The contaminants have been in contact with these sediments for up to 30 years. $\mathrm{CCl}_{4}$ and $\mathrm{CHCl}_{3}$ partition coefficients ranged from $0.106 \mathrm{~L} / \mathrm{kg}$ to $0.367 \mathrm{~L} / \mathrm{kg}$ and $0.084 \mathrm{~L} / \mathrm{kg}$ to $0.432 \mathrm{~L} / \mathrm{kg}$, respectively. These values were 3 to 8 times and 12 to 23 times larger, respectively, than would be predicted based on the organic carbon content of the sediments $(0.017$ to $0.059 \%)$.

These partition coefficients, along with groundwater concentrations of $\mathrm{CCl}_{4}$ and $\mathrm{CHCl}_{3}$ measured at the same location of sediment collection, were used to estimate sediment concentrations of $\mathrm{CCl}_{4}$. In some cases, predicted values were significantly higher than observed sediment concentrations of $\mathrm{CCl}_{4}$ (e.g., $904 \mu \mathrm{g} / \mathrm{kg}$ calculated versus $31.8 \mu \mathrm{g} / \mathrm{kg}$ observed). A likely rationale for this difference is degradation of $\mathrm{CCl}_{4}$ in the sediments. A significant fraction of $\mathrm{CHCl}_{3}(61 \%$ to $70 \%$ of the total solute mass) was observed to be resistive to desorption from some of the sediments. The apparent sequestering properties of these sediments suggest that a certain portion of the $\mathrm{CHCl}_{3}$ in Hanford aquifer sediments is migrating more slowly in groundwater than would be predicted by simple partitioning between groundwater and sediment.

Past modeling of the $\mathrm{CCl}_{4}$ transport in the Hanford groundwater aquifer has assumed conservative values for contaminant partitioning (e.g., a $\mathrm{K}_{\mathrm{d}}$ value of 0 and no degradation), resulting in predictions that $\mathrm{CCl}_{4}$ concentrations will exceed compliance limits on the 200 Area plateau and at the Columbia River within a 1,000 year time frame. Use of the $\mathrm{K}_{\mathrm{d}}$ values determined in this study in transport simulations would result in slower predicted migration rates and reduced uncertainty. The presence of significant concentrations of $\mathrm{CHCl}_{3}$ in the presence of lower-than-expected concentrations of $\mathrm{CCl}_{4}$ indicated $\mathrm{CCl}_{4}$ degradation in the sediment and the need to more accurately represent this process in transport modeling. 


\section{Contents}

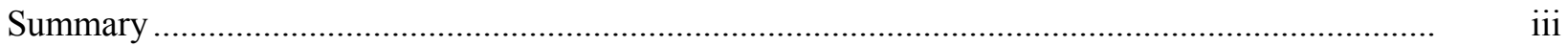

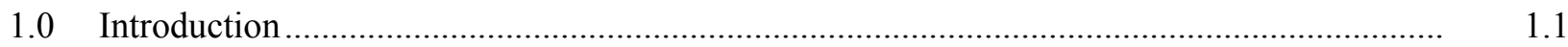

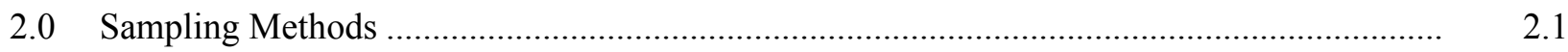

2.1 Collection of Intact Sediment Cores.....................................................................

2.2 Conversion of Liners to Intact Core Transport Containers …...................................... 2.1

2.3 Conversion of Transport Containers into Desorption Columns ................................... 2.3

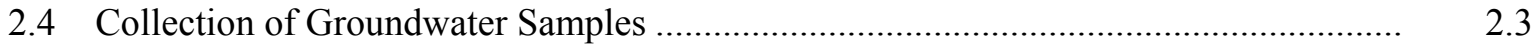

3.0 Sample Preparation and Analysis Methodology ........................................................... 3.1

3.1 Sediment Moisture Content ...................................................................................

3.2 Bulk Fraction Distribution Analysis................................................................... 3.1

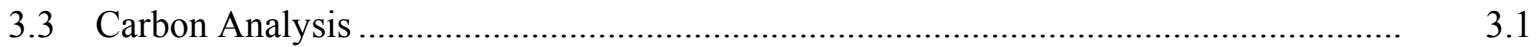

3.4 Analysis of Water Samples by Gas Chromatography/Mass Spectrometry .................. 3.2

3.5 Accelerated Solvent Extraction of Sediments ..........................................................

3.6 Analysis of Sediment Extracts by Gas Chromatography .........................................

$4.0 \quad$ Experimental Desorption System and Solute Elution .......................................................

5.0 Tracer/Solute Profile Simulations from 1-D Column Experiments ....................................... 5.1

5.1 Partition Coefficients from Profile Determination of Retardation Factors ................... 5.1

5.2 Model Simulations to Assess Tracer/Solute Behavior ................................................

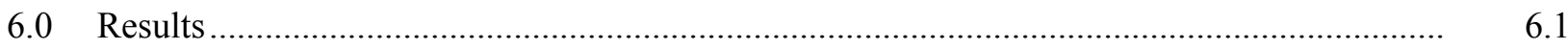

6.1 Physical and Chemical Characteristics of Sediment Cores ............................................

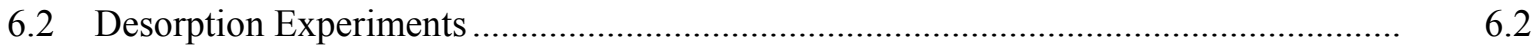

6.2.1 $\mathrm{CCl}_{4}$ and $\mathrm{CCl}_{3}$ Behavior in Column Desorption Experiments ......................... 6.2

6.2.2 Simulation of Tracer Behavior in 1-D Column Experiments ............................. 6.6

6.2.3 Simulation of $\mathrm{CCl}_{4}$ Behavior in Column Desorption Experiments ................... 6.6

6.2.4 Simulation of Chloroform Behavior in Column Desorption Experiments........ $\quad 6.10$

6.3 Carbon Tetrachloride and Chloroform Residuals in Sediment Cores .......................... 6.10

6.4 Initial Sediment Core Solute Concentrations .................................................................

6.5 Concentrations of Solutes in Samples of Groundwater Collected at Sediment

Depth Locations …….......................................................................................... 6.12 


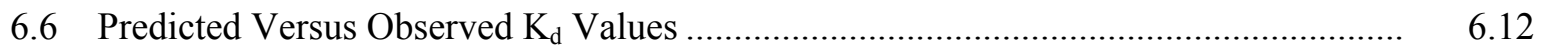

6.7 Predicted Versus Observed Sediment Core Solute Concentrations ............................. 6.13

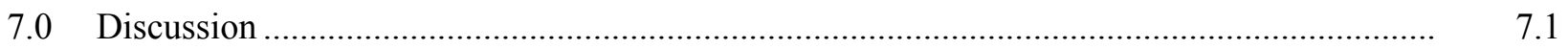

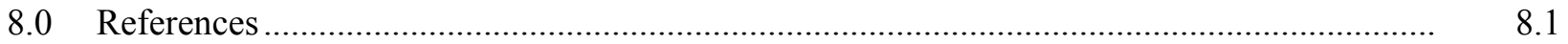

Appendix A - Calculation of CH Concentration from GC-MS Data

Appendix B - Column Experiment Breakthrough Data

\section{Figures}

1.1 Location of C3426 Borehole Relative to 216-Z-9 Trench ................................................. 1.2

2.1 Aquifer Sediment in Liner from Hanford Site Subsurface .............................................. 2.2

2.2 Disassembled Core Transport Container. ........................................................................... 2.2

4.1 Transport Container Converted into Desorption Column s. .............................................. 4.2

6.1 Particle Size Distribution in Aquifer Sediment Core Samples ........................................... 6.2

6.2 Tracer and Carbon Tetrachloride Breakthrough Data for Column

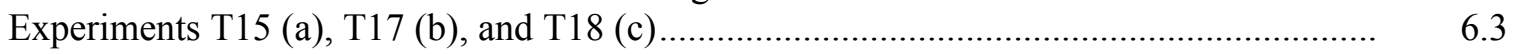

6.3 Tracer and Chloroform Breakthrough Data for Column Experiments T17 (a) and $\mathrm{T} 18$ (b).

6.4 Conservative Tracer Breakthrough Data for Column Experiments

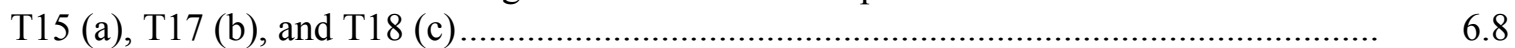

6.5 Carbon Tetrachloride Breakthrough Data for Column Experiments T15 (a), T17 (b), and T18 (c)

6.6 Chloroform Breakthrough Data for Column Experiments T17 (a) and T18 (b) Carbon Tetrachloride and Chloroform Residuals in Sediment Cores.

\section{Tables}

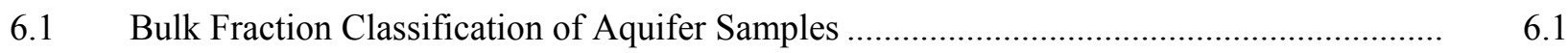

6.2 Carbon Analysis of Aquifer Core Samples ....................................................................

6.3 Column Experiment Solute Mass Retardation and Mass Balance...................................... 6.5

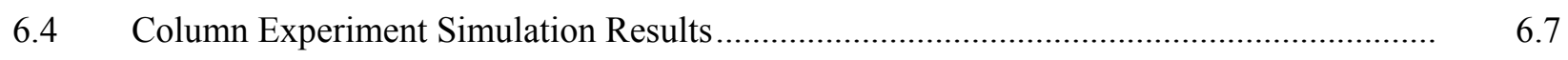

6.5 Initial Concentrations of $\mathrm{CCl}_{4}$ and $\mathrm{CHCl}_{3}$ in Sediment Cores ....................................... 6.11 


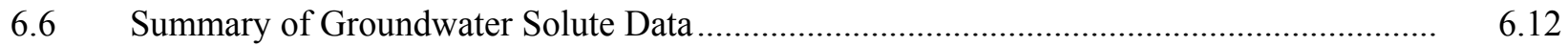

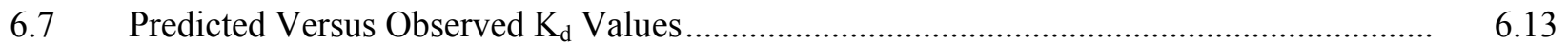

6.8 Predicted Versus Observed Sediment Solute Concentrations.............................................. 6.13 


\subsection{Introduction}

Fluor Hanford, Inc. (FHI) has identified data needs that are critical to locating, characterizing, and assessing the impact of carbon tetrachloride $\left(\mathrm{CCl}_{4}\right)$ contamination underlying the 200 West Area on the Hanford Site. These needs have been summarized in a data quality objectives summary report (Bauer and Rohay et al. 2004). One need, identified by the U.S. Environmental Protection Agency (EPA) and described in this report, is to establish partition coefficients between gas, liquid, and solid phases for $\mathrm{CCl}_{4}$ based on naturally contaminated sediments and to use such data to refine the fate and transport modeling performed to assess the impacts of the $200 \mathrm{West}$ Area $\mathrm{CCl}_{4}$ plume. This need is consistent with FHI's objective to clean up and protect Hanford groundwater by conducting a field investigation of $\mathrm{CCl}_{4}$ dense non-aqueous phase (DNAPL).

With no liquid-phase/solid-phase partition coefficient $\left(\mathrm{K}_{\mathrm{d}}\right)$ values available for $\mathrm{CCl}_{4}$ in Hanford sediments, past modeling of Hanford's $\mathrm{CCl}_{4}$ plume relied on an estimate of the $\mathrm{K}_{\mathrm{d}}$ and associated uncertainty derived from a normalized sorption coefficient $\left(\mathrm{K}_{\mathrm{oc}}\right)$ from the literature and what is known about the range in organic carbon content of Hanford sediments (Truex et al. 2001; Hartman et al. 2002). The $\mathrm{K}_{\mathrm{d}}$ value (based on $\mathrm{K}_{\mathrm{oc}}$ ) for $\mathrm{CCl}_{4}$ in a Hanford soil with an average organic carbon content of $0.2 \%$ was estimated to be in the range of 0.016 to $0.83 \mathrm{~L} / \mathrm{kg}$ with a most probable value of $0.12 \mathrm{~L} / \mathrm{kg}$ (Truex et al. 2001). The magnitude of partition coefficient values applied in modeling $\mathrm{CCl}_{4}$ migration in Hanford groundwater has been shown to be critical in determining whether compliance limits will be exceeded outside the Central Plateau waste management area (Hartman et al. 2001; Bergeron and Cole 2004).

This report summarizes the results of aqueous desorption laboratory experiments conducted in a column apparatus with intact cores of aquifer sediments to determine values of $\mathrm{K}_{\mathrm{d}}$ for $\mathrm{CCl}_{4}$ and $\mathrm{CHCl}_{3}$. Also discussed are the effects of long contact time on $\mathrm{CCl}_{4}$ and $\mathrm{CHCl}_{3}$ behavior in Hanford aquifer sediments. Sediment samples were collected from borehole C3426 (299-W15-46) drilled in the 200 West Area as part of the field investigation of $\mathrm{CCl}_{4}$ DNAPL being performed by FHI (Figure 1.1). Samples were collected from four different depths in the groundwater aquifer and determined to be contaminated with $\mathrm{CCl}_{4}, \mathrm{CHCl}_{3}$, methylene chloride, and trichloroethene. 


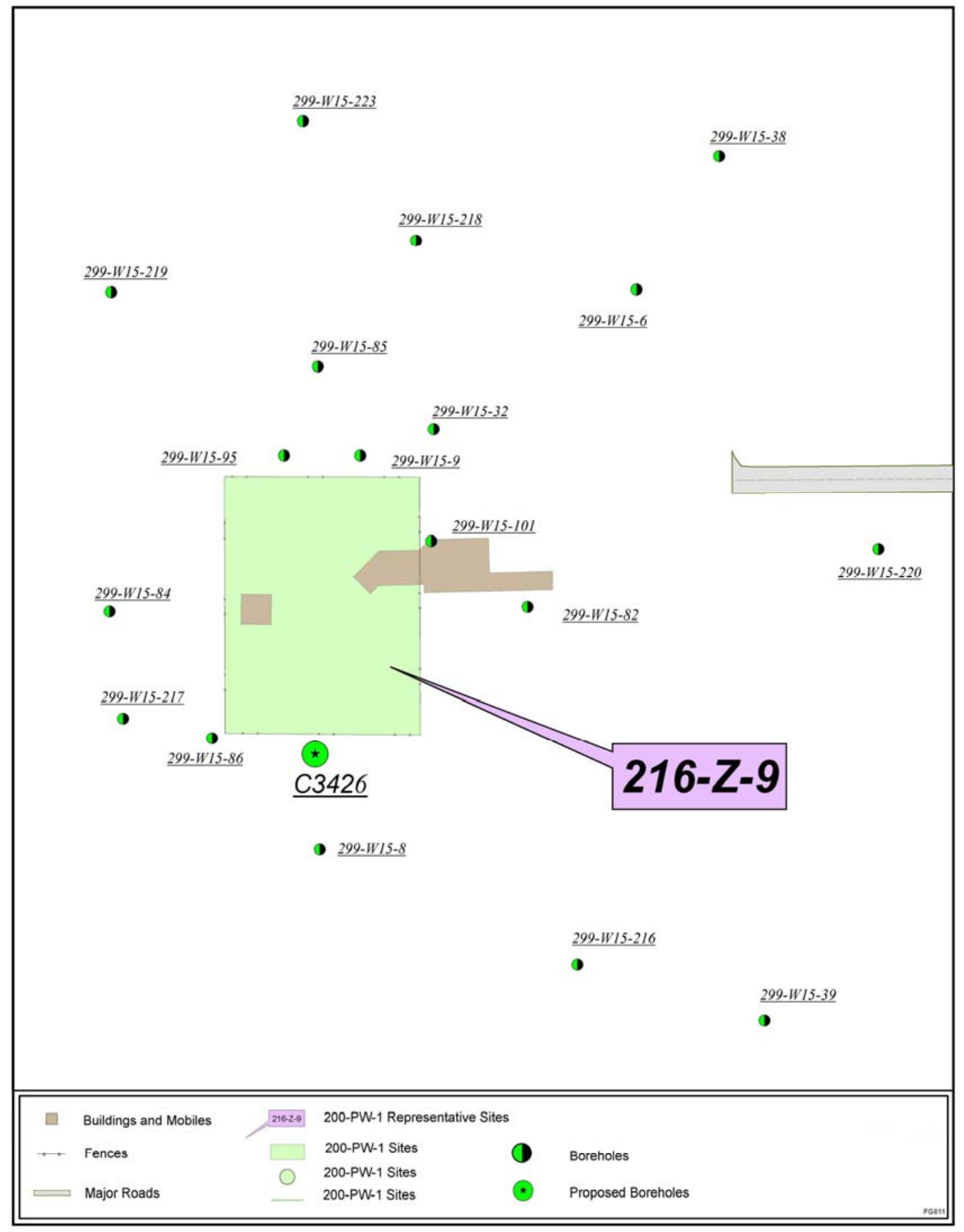

Figure 1.1. Location of C3426 Borehole (299-W15-46) Relative to 216-Z-9 Trench 


\subsection{Sampling Methods}

\subsection{Collection of Intact Sediment Cores}

Sediment cores were collected from borehole 299-W15-46 in the 200 West Area at a location approximately 6 meters (20 feet) from the south boundary of the 216-Z-9 trench (Figure 1.1). Samples were collected from depths of 70 to 70.7 meters (230 to 232 feet), 89 to 89.6 meters (292 to 294 feet), 111 to 111.6 meters (364 to 366 feet), and at 131 to 131.7 meters ( 430 to 432 feet) below ground surface in the unconfined aquifer.

Intact sediment cores were collected in split spoon samplers ( 0.6 meter [ 2 feet] in length) that contained four threaded stainless liners $(0.6$ centimeter [ 0.25 inch] thick by 10.2 centimeters [ 4 inches] outside diameter by 15.2 centimeters [ 6 inches] in length and knurled at the center of its outside diameter). Samplers were driven into the aquifer to a depth of approximately 0.5 meter ( 1.75 feet), minimizing potential damage to individual liners resulting from over driving the split spoon. Employing this process, up to three of the four liners could be recovered for use in experimental studies. One or two liners were set aside for column desorption experiments and one for sediment physical/chemical characterization.

\subsection{Conversion of Liners to Intact Core Transport Containers}

The split spoon samplers were brought to the surface and opened. Individual liners were separated from each other. Thin sharp-edged stainless steel plates were inserted between liners to render clean separation and prevent loss of sediment and pore water from each liner. Samples to be used for desorption experiments were examined to ensure that they were completely filled with sediment. Figure 2.1 shows a liner filled with sediment from a depth of 111 to 111.9 meters (364 to 367 feet) in the aquifer.

Stainless steel frits (20 mesh on one side and 40 mesh on the other side) were placed at each open end of separated liners targeted for aqueous desorption experiments. The frits were put in place to prevent sediment loss from the liners during desorption experiments. The frits were followed with stainless steel spacers, to eliminate headspace, and two stainless steel endcaps. Each end cap was knurled on its side and had a hole in its center that was closed off with a brass plug. Teflon tape was placed across the liner threads and the edges of the frit and spacer to seal the sample so it would not leak prior to placing the endcap (Figure 2.2). Endcaps were tightened using strap wrenches along the knurled surfaces. The completed assembly was designated an intact core transport container. The transport container for the liner containing sediment for physical/chemical characterization consisted of the liner sealed with brass endcaps only (i.e., no frits and stainless steel spacers). 


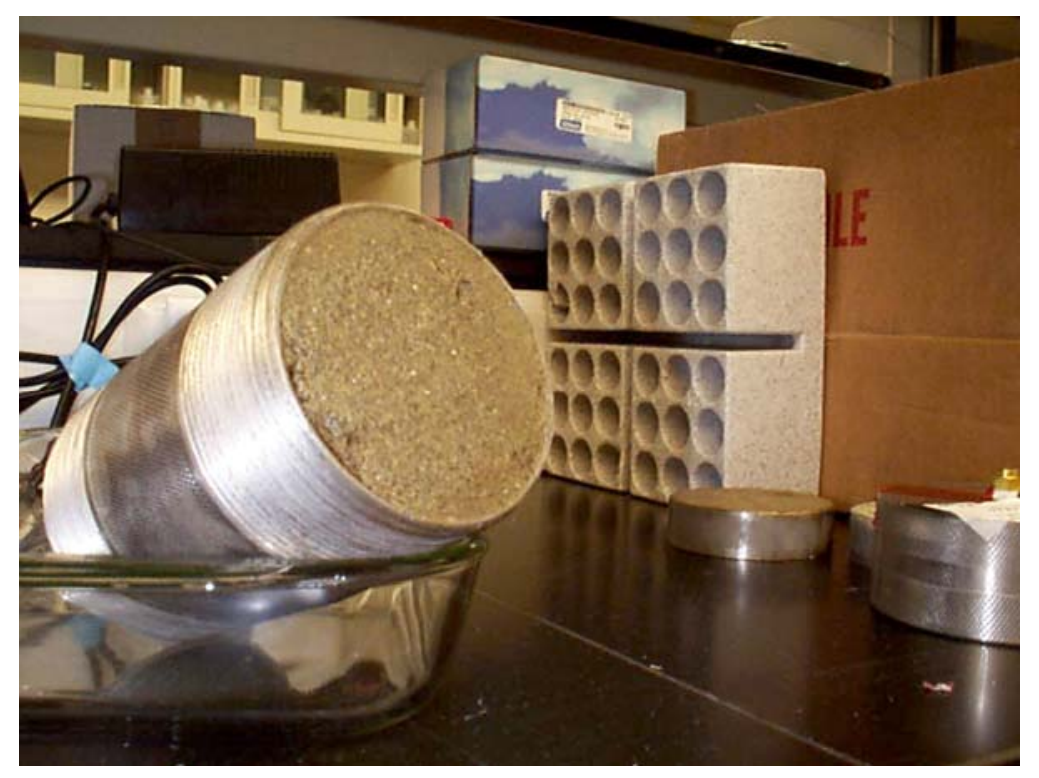

Figure 2.1. $\quad$ Aquifer Sediment in Liner from Hanford Site Subsurface (111 to 111.9 meters [364 to 366 feet])

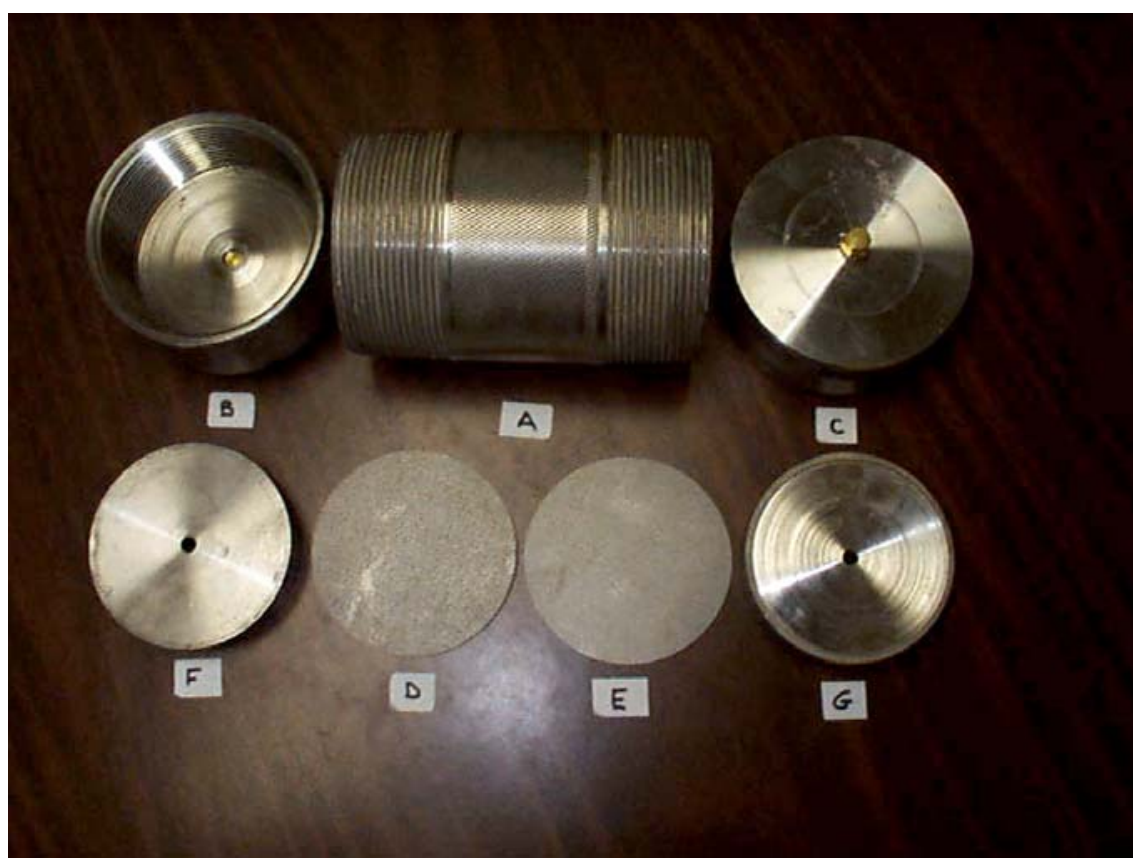

Figure 2.2. Disassembled Core Transport Container. Individual Components are: (A) sample liner, (B) endcap, internal view, (C) endcap, external view showing brass plug, (D) 40 mesh stainless steel frit, (E) 20 mesh stainless steel frit, (F) stainless steel spacer side that faces endcap, $(G)$ stainless steel spacer side that faces stainless steel frit and is recessed to allow uniform distribution of influent and effluent across core section during conduct of column desorption experiments. 
Each transport container was placed in a chest containing crushed ice and was transported to the laboratory at the end of the day and subsequently refrigerated. Those samples not delivered at the end of the day were refrigerated in FHI's holding facility for delivery the following day. To eliminate concerns for sample stability (i.e., potential solute degradation), column desorption experiments were initiated within a week of receipt at the laboratory. This timeframe is well within the recommended 14-day holding time for analysis of volatile organic compounds in sediments and groundwaters (EPA 1996).

\subsection{Conversion of Transport Containers into Desorption Columns}

During split spoon sampling, sediments were compacted in the liners at densities greater than were present in the aquifer environment. Therefore, back pressure of up to $100 \mathrm{psi}$ was anticipated when aqueous influent was pumped into columns during desorption experiments. Removing endcaps from the transport containers and resealing the end caps with liquid pipe glue prior to column setup eliminated the potential for influent/effluent leakage during desorption experiments.

Brass plugs in each end of the transport container were replaced by stainless steel fittings at the initiation of desorption experiments in the laboratory. Each stainless steel spacer was recessed on the side facing the frit to allow cross-sectional distribution of influent and collection of effluent from the column cross section during desorption.

\subsection{Collection of Groundwater Samples}

Triplicate groundwater samples were collected in 40-milliliter volatile organic analysis (VOA) vials at three of the four aquifer depths from which split spoon samples were collected. Samples were collected using a submersible pump. Vials were filled to the top to eliminate headspace and capped. Samples were stored on ice in the field, brought back to the laboratory at the end of the day, and analyzed within a week of collection. 


\subsection{Sample Preparation and Analysis Methodology}

\subsection{Sediment Moisture Content}

Gravimetric water contents of the sediment samples from borehole 299-W15-46 were determined using the approved PNNL procedure, which is based on the American Society for Testing and Materials procedure Test Method for Laboratory Determination of Water (Moisture) Content of Soil and Rock by Mass (ASTM D2216-98 [ASTM 1998]). Representative duplicate subsamples of at least 20 to 80 grams were taken from each jar. Sediment samples were placed in tared containers, weighed, and dried in an oven at $105^{\circ} \mathrm{C}\left(221^{\circ} \mathrm{F}\right)$ until constant weight was achieved, which took at least 24 hours. The containers were removed from the oven, sealed, cooled, and weighed. At least two weighings, each after a 24-hour heating, were performed to ensure that all moisture was removed. All weighings were performed using a calibrated balance. A calibrated weight set was used to verify balance performance before weighing samples. The gravimetric water content was computed as the percentage change in soil weight before and after oven drying.

\subsection{Bulk Fraction Distribution Analysis}

The wet sieving/hydrometer method was performed in duplicate to determine the particle size distribution of all four of the samples from borehole 299-W15-46. The hydrometer technique is described in ASA (1986a), Part 1, Method 15-5, "Hydrometer Method;" the method quantifies the relative amounts of silt and clay. Sample aliquots that were used for the hydrometer method were never air- or oven-dried to minimize the effects of particle aggregation that can affect the separation of clay grains from the coarser material. The particle density of bulk grains from the samples are usually determined using pychnometers as described in ASA (1986b) Part 1, Method 14-3, "Pychnometer Method" using ovendried material. The particle density is an input needed to determine the particle size when using the hydrometer method. However, no direct particle density measurements were made for the four sediments analyzed as part of this investigation, and the particle-size data reported in this document used the quartz default value of $2.65 \mathrm{grams} / \mathrm{cm}^{3}$ to calculate the particle size distribution. The error in using this simplifying assumption has been shown to be insignificant when applied to Hanford sediments (Serne et al. 2004).

\subsection{Carbon Analysis}

The carbon content of the sediment samples was determined (in duplicate) using ASTM Method D4129-88, Standard Methods for Total and Organic Carbon in Water by High Temperature Oxidation and by Coulometric Detection (ASTM 1988). Total carbon in all samples was determined using a Shimadzu TOC-V Total Organic Carbon analyzer with combustion at approximately $980^{\circ} \mathrm{C}\left(1,796^{\circ} \mathrm{F}\right)$. Ultrapure oxygen was used to sweep the combustion products through a barium chromate catalyst tube for conversion to carbon dioxide. Evolved carbon dioxide was quantified through coulometric titration following absorption in a solution containing ethanolamine. The analyzer reported carbon-content values in micrograms per sample. Soil samples for determining total carbon content were placed into pre-combusted, tared platinum combustion boats and weighed on a four-place analytical balance. After 
the combustion boats were placed into the furnace introduction tube, a 1-minute waiting period was allowed so that the ultrapure oxygen carrier gas could remove (i.e., sparge) any carbon dioxide introduced to the coulometric system from the atmosphere during sample placement. After this system sparge, the sample was moved into the combustion furnace and the titration was begun. Sample titration readings were performed at 3 minutes after combustion began and again once stability was reached, usually within the next 2 minutes. The system background was determined by performing the entire process using an empty, pre-combusted platinum boat. Adequate system performance was confirmed by analyzing for known quantities of a calcium carbonate standard.

Inorganic carbon contents for the sediment samples (also performed in duplicate) were determined using a Shimadzu TOC-V Total Organic Carbon Analyzer. Soil samples were weighed on a four-place analytical balance and then placed into acid-treated glass tubes. Following placement of sample tubes into the system, a one-minute waiting period allowed the ultrapure oxygen carrier gas to remove any carbon dioxide introduced to the system from the atmosphere. Inorganic carbon was released through acid-assisted evolution (50\% hydrochloric acid) with heating to $200^{\circ} \mathrm{C}\left(392^{\circ} \mathrm{F}\right)$. Samples were completely covered by the acid to allow full reaction to occur. Ultrapure oxygen gas swept the resultant carbon dioxide through the equipment to determine inorganic carbon content by coulometric titration. Sample titration readings were performed 5 minutes following acid addition and again once stability was reached, usually within 10 minutes. Known quantities of calcium carbonate standards were analyzed to verify that the equipment was operating properly. Background values were determined. Inorganic carbon content was determined through calculations performed using the microgram per-sample output data and sample weights. Organic carbon was calculated as the difference between the measured total and inorganic carbon.

\subsection{Analysis of Water Samples by Gas Chromatography/Mass Spectrometry}

A stock standard solution containing $\mathrm{CCl}_{4}$ (Aldrich, 99.9+\% HPLC grade), $\mathrm{CHCl}_{3}$ (Burdick and Jackson, GC2 grade), and trichloroethene (EM, ACS grade) at approximately 10,000 $\mathrm{mg} / \mathrm{L}$ in methanol (Fisher Chemical, purge and trap grade) was prepared. Secondary dilution standards were prepared in methanol. The internal standard, pentafluorobenzene (PFB), at 2,000 $\mu \mathrm{g} / \mathrm{mL}$, was prepared and certified by Supelco.

Groundwater samples were received in 40-milliliter VOA vials for headspace analysis. To analyze these samples, 20 milliliters of water were removed from the vial, and PFB was injected through the septum directly into the water. The vial was stirred for 30 seconds using a vortex mixer and allowed to equilibrate for at least $1 / 2$ hour. Calibration standards were prepared in VOA vials by injecting appropriate volumes of the stock standard and PFB solutions through the septum directly into milli-Q grade water, then stirring and equilibrating as above.

Effluent samples from desorption experiments were received in 125- or 154-milliliter bottles with septum caps. PFB was injected through the septum. The bottle was shaken for 30 seconds by hand and allowed to equilibrate for at least $1 / 2$ hour. Because different amounts of water were present in the bottles (ranging from $<1$ milliliter to almost 100 milliliters [but typically in the 10 to 30 milliliters range]) 
standards were prepared using a range of water volumes. The standard and internal standard were both added directly into the water, and the bottles were capped, shaken, and equilibrated.

An aliquot of the headspace from either the VOA vial or the sample bottle was injected using a gas-tight syringe into a Hewlett Packard 5890 GC-MS equipped with a gas-sampling loop to identify and quantify solute compounds. Solutes were separated from each other using a J\&W Scientific DB-1 column (60 meters [197 feet] by 0.32 millimeters [0.01 inch]) with a 1.6 milliliter/minute helium flow rate. The initial column temperature was $40^{\circ} \mathrm{C}\left(104^{\circ} \mathrm{F}\right)$ with a 4-minute isothermal hold; the temperature was then increased at $20^{\circ} \mathrm{C}\left(68^{\circ} \mathrm{F}\right) /$ minute to $220^{\circ} \mathrm{C}\left(428^{\circ} \mathrm{F}\right)$ and held isothermal for 1 minute. The mass spectrometer was operated in electron impact ionization mode. In most of the desorption experiments, detection was by single ion monitoring of the following ions (amu): $\mathrm{CCl}_{4} 116.8,118.8, \mathrm{CHCl}_{3} 83.0$, 85.0; trichloroethene 130.0, 132.0; PFB 168.0, 99.0. Scan mode was used for the groundwater samples and part of the first desorption experiment; the scan range was from 33 to $250 \mathrm{amu}$. Six point calibration curves were prepared and were found to be linear for a range of $20 \mathrm{ppb}$ to $3 \mathrm{ppm} \mathrm{CCl}_{4}$; a continuing calibration standard was used for analyses.

\subsection{Accelerated Solvent Extraction of Sediments}

A DIONEX accelerated solvent extraction system (ASE-200) was used for the extraction of residual $\mathrm{CCl}_{4}, \mathrm{CHCl}_{3}$, methylene chloride, and trichloroethene from the post column desorption experiment sediments using methanol as the extraction solvent.

Each sample of sediment was placed in a 33-milliliters-stainless-steel sample tube capped at both ends. Both caps had small openings: one to deliver methanol into the tube through the needle and the other to remove methanol extract.

To prevent losses of solutes through the openings, each soil sample was sandwiched between two layers of clean Ottawa sand. Normally, 13 to 15 grams of the sand was placed at the bottom of the tube followed by about 20 grams of wet soil and on top of the soil another 13 to 15 grams of the sand. Tubes were placed in the rotating tray of ASE-200 and heated to $40^{\circ} \mathrm{C}\left(104^{\circ} \mathrm{F}\right)$. Upon reaching $40^{\circ} \mathrm{C}\left(104^{\circ} \mathrm{F}\right), 14$ $\mathrm{ml}$ of methanol was injected under pressure into each tube. Following injection, tubes were held 5 minutes at $40^{\circ} \mathrm{C}\left(104^{\circ} \mathrm{F}\right)$. Following the 5-minute hold, methanol, under the high pressure of ultra-high purity nitrogen, was displaced from the tube and collected in 60-milliliter vials. This cycle was repeated three times. The volume of the extract ranged from 37 to 41 milliliters, depending on the dryness of the sample.

Recovery of $\mathrm{CCl}_{4}$ from sediments using accelerated solvent extraction was determined for extraction temperatures ranging from $40^{\circ} \mathrm{C}\left(104^{\circ} \mathrm{F}\right)$ to $100^{\circ} \mathrm{C}\left(212^{\circ} \mathrm{F}\right)$. It was found that $40^{\circ} \mathrm{C}\left(104^{\circ} \mathrm{F}\right)$ was optimal for the extraction of $\mathrm{CCl}_{4}$. Recovery of aqueous solutions of $\mathrm{CCl}_{4}$ spiked into sediments was between 82 and $101 \%$, depending on the type of soil. Recovery of other solutes was assumed to be similar to $\mathrm{CCl}_{4}$. We believe that most of the losses occurred between the moment of spiking the sample with $\mathrm{CCl}_{4}$ solution when the sample was and covered with the layer of the sand. 


\subsection{Analysis of Sediment Extracts by Gas Chromatography}

Methanol extracts of sediments were diluted 50-200 times in boiled Milli-Q water and analyzed using a Hewlett Packard 5890 gas chromatograph fitted with a purge and trap system with photoionization and electron capture detectors. Solute compounds were separated on a 105 meter by 0.53 millimeter megabore capillary column (Restek Corporation) and quantified using a four-point calibration. Calibration standards were prepared from a commercial standard consisting of 14 volatile hydrocarbons in methanol (Restek 502.2 Calibration Mix \#2). 


\subsection{Experimental Desorption System and Solute Elution}

A column desorption experiment consisted of injecting groundwater from a well in Hanford's 100 Area (i.e., free of $\mathrm{CCl}_{4}$ and $\mathrm{CHCl}_{3}$ ) into the solute-laden sediment core at a constant flow rate for up to a maximum of 20 pore volumes and collecting effluent samples for solute $\left(\mathrm{CCl}_{4}, \mathrm{CHCl}_{3}\right)$ analysis (Figure 4.1). The column system was built specifically to minimize mass loss of the volatile solutes during the desorption experiment. A 5-liter bottle containing oxygen-saturated Hanford groundwater was connected to an Hitachi L-6200 HPLC pump, which supplied a constant flow rate (0.42 to 0.54 milliliters per minute, depending on experiment) through stainless steel tubing to the column inlet (total volume $1,010 \mathrm{~cm}^{3}$ ). The column effluent (flow vertically up in Figure 4.1) was plumbed to a flow-through electrical conductivity (EC) electrode (20-microliter volume), then to a Kloehn syringe pump with eight-channel multiplexing head. The EC electrode was connected to an EC meter and data logging system and used to monitor the conservative tracer. EC data was collected at a rate of 2 points per second and averaged for 1 minute. The conservative tracer breakthrough consisted of the small change in electrical conductivity between the groundwater in the sediment column and influent water. The Kloehn syringe pump was connected to seven 154 milliliter septa-top glass bottles and a large waste bottle. The syringe pump was used as a fraction collector, where column effluent flowed into a septa-top bottle for 74 minutes (30 milliliters), then into the waste bottle for a specified time (0 to 40 hours). Sample collection frequency was designed to collect more samples during initial breakthrough $(<2 \mathrm{pv})$, and less samples along the "tail" of the break through curve ( 2 to $20 \mathrm{pv}$ ). Between 0 and 1.75 pore volumes, the sample collection frequency was one per 75 minutes. From 1.75 to 5 pore volumes the sample collection frequency was one per 300 minutes. From 5 to 20 pore volumes, the sample collection frequency was one per 40 hours, giving a total experiment time of 200 to 220 hours.

The 30 milliliters of aqueous effluent in the sealed septa-top vials were expected to achieve liquid-gas phase equilibrium within 40 to 96 hours before GC-MS analysis of the solutes in the vapor phase. Henry's Law (at $25^{\circ} \mathrm{C}\left[77^{\circ} \mathrm{F}\right]$ ) was used to calculate the total solute mass originally in the liquid given the gas phase measurement, as described in Appendix A. A total of four column experiments were conducted (named T15, T17, T18, and T19), with effluent data profiles of electrical conductivity (i.e., nonreactive tracer) and $\mathrm{CCl}_{4}$ and/or $\mathrm{CHCl}_{3}$ concentration with time (Appendix B). Column porosity was calculated from values of sediment wet weight and dry weight for each column experiment. The dry bulk density was calculated from sediment dry weight and total column volume for each experiment. The flow rate for all column experiments was chosen to be 10 to 5 hours per pore volume, which was considered sufficient time for solutes to desorb from the sediment or organic matter surfaces (assuming no extremely slow physical or chemical kinetic processes are occurring) and produce desorption profiles for simulation modeling and determination of $\mathrm{CCl}_{4}$ and $\mathrm{CHCl}_{3}$ partition coefficients.

After completion of an experiment, the column was dismantled, and subsamples of the sediment core were analyzed for solutes according to procedures described in Sections 3.4 and 3.5. 


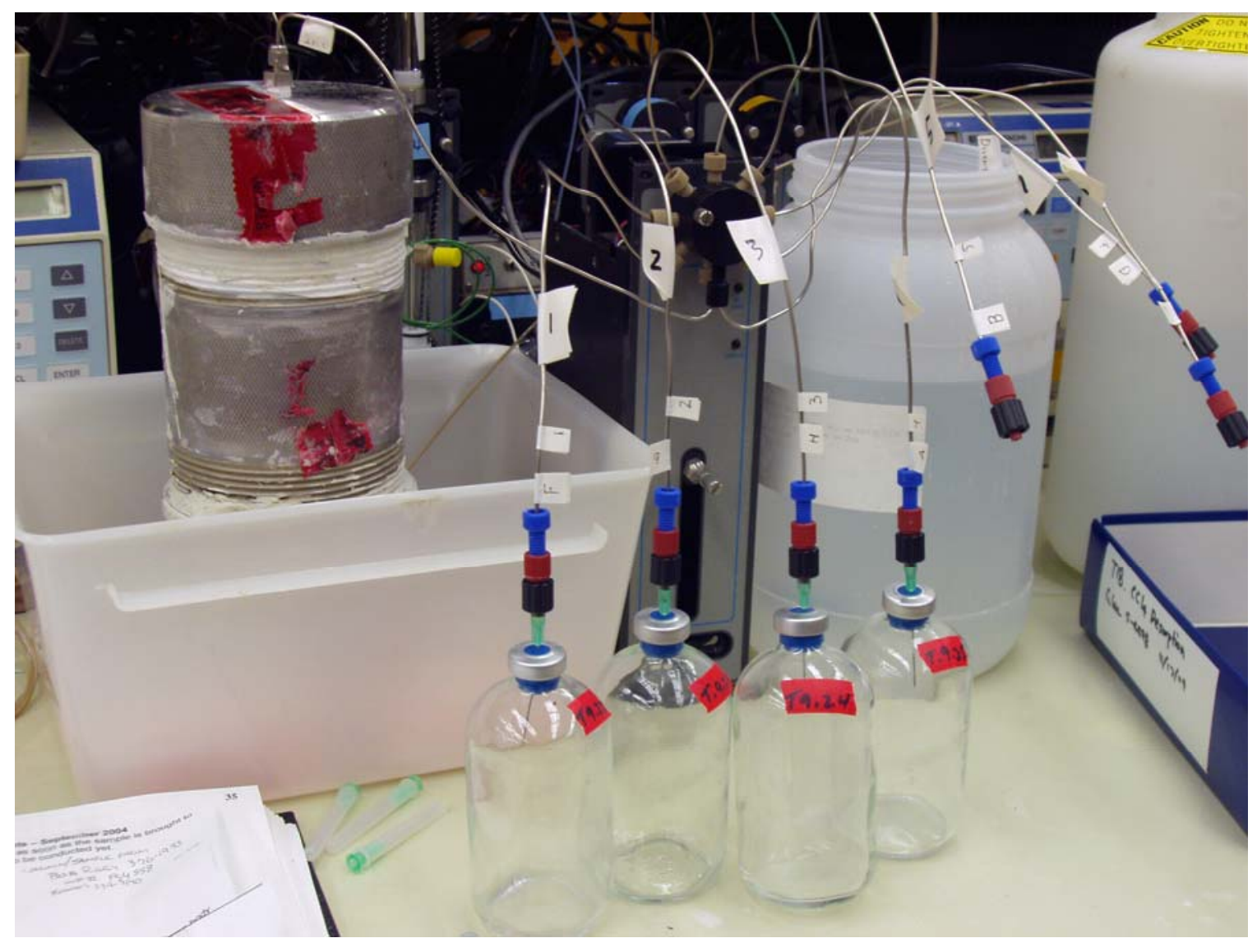

Figure 4.1. Transport Container Converted into Desorption Column. Column shown connected to multiple switching valve to which is attached multiple column effluent bottles. 


\subsection{Tracer/Solute Profile Simulations from 1-D Column Experiments}

\subsection{Partition Coefficients from Profile Determination of Retardation Factors}

The "retardation factor" $\left(\mathrm{R}_{\mathrm{f}}\right)$ is defined by the ratio of velocities of the tracer/solute so that a value of 1.0 indicates no sorption (solute travels at the same velocity as the tracer) and a value $>1.0$ indicates sorption. With no additional assumption as to the sorption mechanism or rate, the solute retardation factor was determined by integrating the area in front of the solute breakthrough curve. The sorption mass parameter $\mathrm{K}_{\mathrm{d}}\left(\mathrm{cm}^{3} / \mathrm{g}\right.$ or $\left.\mathrm{L} / \mathrm{Kg}\right)$ is defined by the mass of solute on the sediment surface (per gram of sediment) to the mass of solute in aqueous solution (per milliliters of solution), and can be calculated from $\mathrm{R}_{\mathrm{f}}$ by:

$$
\mathrm{R}_{\mathrm{f}}=1+\square_{\mathrm{b}} \mathrm{K}_{\mathrm{d}} / \square
$$

where $\square_{b}$ is the dry bulk density $\left(\mathrm{g} / \mathrm{cm}^{3}\right)$ and $\square$ is the total porosity. Reactive transport simulations of breakthrough was additionally done to validate different conceptual models that describe solute sorption/desorption (described in the following section).

\subsection{Model Simulations to Assess Tracer/Solute Behavior}

Three different reactive transport models were used to quantify kinetic parameters that describe solute slow sorption/desorption and diffusion of tracer and solute between mobile and immobile pore fluid pore fluid. These models were:

- equilibrium model - incorporates advective/dispersive flux and rapid (equilibrium) sorption

- first-order model - incorporates advective/dispersive flux and first-order reversible slow (kinetic) sorption/desorption

- two-region model - incorporates advective/dispersive flux, equilibrium and first-order kinetic sorption or diffusion between mobile and immobile pore fluid and equilibrium sorption in both regions.

A systematic approach was used to determine model parameters independently of fitting multiple parameters to a single breakthrough curve because both hydrodynamic dispersion and slow sorption/ desorption will define the solute breakthrough curve shape. This required using the $\mathrm{K}_{\mathrm{d}}$ values determined from area integration (described above) and using longitudinal dispersivity $\left(\mathrm{D}_{\mathrm{L}}\right)$ values from fitting tracer breakthrough data. Longitudinal dispersivity $\left(D_{L}\right)$ is defined by the physical breakthrough curve spreading that occurs as a nonsorbing (conservative) tracer flows through a 1-D porous media column:

$$
\mathrm{D}_{\mathrm{L}}=\mathrm{D}_{\mathrm{o}}+\square_{\mathrm{L}} \mathrm{v}
$$

where $\mathrm{D}_{\mathrm{o}}$ is molecular diffusion, $\mathrm{C}_{\mathrm{L}}$ is the longitudinal dispersivity, and $\mathrm{v}$ is the interstitial velocity. Idealized transport of a sorbing solute in the same homogeneous sediment column will have the same 
longitudinal dispersion (producing breakthough curve spreading) but will lag relative to the tracer due to the reversible sorption/desorption (i.e., $\mathrm{R}_{\mathrm{f}}$ ). A pore volume is defined by the volume of water in the sediment column that is subjected to advective/dispersive transport. The reactive transport model that describes rapid (equilibrium) sorption, advection, and dispersion is described by the differential equation:

$$
\frac{\mathrm{R}_{\mathrm{f}} \square_{\mathrm{b}}}{\square} \frac{\partial \mathrm{S}}{\partial \mathrm{t}}=\mathrm{D}_{\mathrm{L}} \frac{\partial^{2} \mathrm{C}}{\partial \mathrm{z}^{2}}-\mathrm{v} \frac{\partial \mathrm{C}}{\partial \mathrm{z}}
$$

The model includes three parameters; velocity $(\mathrm{v})$, retardation factor, $\left(\mathrm{R}_{\mathrm{f}}\right)$, and longitudinal dispersion $\left(\mathrm{D}_{\mathrm{L}}\right)$ to describe the rate of change in the solute or tracer aqueous concentration $(\mathrm{C})$ or surface concentration (S), as first described by Gleuckauf (1947). An analytical solution to this model with a nonlinear least squares parameter estimation routine was first described by van Genuchten and others $(1974,1979)$, and used here in it's current form (CXTFIT, Toride et al. 1993, 1999). In this study the tracer data was fit with the equilibrium model to determine the longitudinal dispersion, with a defined velocity and defined retardation factor (1.0; i.e., the velocity and retardation factor were not allowed to vary in the simulation, only the dispersion). Next, the solute data was fit with this equilibrium model with the velocity fixed and longitudinal dispersion fixed at the tracer value (i.e., allowing $\mathrm{R}_{\mathrm{f}}$ to vary). If the solute data could be well fit with this equilibrium model simulation, then there was no additional breakthrough curve spreading caused by slow

sorption/desorption of the solute. Additional breakthrough curve spreading (greater than that defined by longitudinal dispersion) indicated slow chemical/physical release of the solute from the surface, and required the use of the first-order or two-region model to approximate the additional kinetic process(es).

The first-order model describes advective-dispersive transport with reversible, linear adsorption/ desorption reaction is defined by the solution to the differential equations

$$
\begin{gathered}
\frac{\partial \mathrm{C}}{\partial \mathrm{t}}+\frac{\square_{\mathrm{b}}}{\square} \frac{\partial \mathrm{S}}{\partial \mathrm{t}}=\mathrm{D} \frac{\partial^{2} \mathrm{C}}{\partial \mathrm{z}^{2}}-\mathrm{v} \frac{\partial \mathrm{C}}{\partial \mathrm{z}} \\
\frac{\square_{\mathrm{b}}}{\square} \frac{\partial \mathrm{S}}{\partial \mathrm{t}}=\mathrm{k}_{\mathrm{f}} \mathrm{C}-\mathrm{k}_{\mathrm{b}} \mathrm{S}
\end{gathered}
$$

with previously defined parameters. This first-order kinetic model contains four parameters; velocity, longitudinal dispersion, and the two reaction rate parameters $\left(\mathrm{k}_{\mathrm{f}}, \mathrm{k}_{\mathrm{b}}\right)$, which are defined by a first-order reversible reaction:

$$
C \stackrel{\mathrm{hr}}{\mathrm{m}} \mathbf{S}
$$


accounts for reversible slow adsorption and slow desorption where $\mathrm{k}_{\mathrm{f}}$ is the forward rate coefficient and $\mathrm{k}_{\mathrm{b}}$ is the backward rate coefficient. Note that $\mathrm{K}_{\mathrm{d}}=\mathrm{S} / \mathrm{C}=\mathrm{k}_{\mathrm{f}} / \mathrm{k}_{\mathrm{b}}$. The first-order kinetic model was first fit to 1-D solute transport data in sediments by Leenheer and Ahlrichs (1971). The first-order model was used in this study with the longitudinal dispersivity fixed, and allowing both retardation factor and $\mathrm{k}_{\mathrm{b}}$ (desorption rate coefficient) to vary to determine if this simple reaction could represent the observed data.

The two-region model describes solute advective/dispersive transport through a porous media with both mobile (subscript "e") and immobile (subscript " $i$ ") pore regions and equilibrium sorption in both regions (van Genuchten et al. 1974), as defined by the differential Equations (5.7) and (5.8)

$$
\begin{gathered}
\square_{e} \frac{\partial C_{e}}{\partial t}+\square_{i} \frac{\partial C_{i}}{\partial t}+f \square_{b} \frac{\partial S_{e}}{\partial t}+(1-f) \square_{b} \frac{\partial S_{i}}{\partial t}=D_{L} \frac{\partial^{2} C_{e}}{\partial z^{2}}-v \square_{e} \frac{\partial C}{\partial z} \\
\square_{i} \frac{\partial C_{i}}{\partial t}+(1-f) \square_{b} \frac{\partial S_{i}}{\partial t}=\square_{e}\left(C_{e}-C_{i}\right)
\end{gathered}
$$

where $f$ is the fraction of sorbent in the mobile region, $C_{e}$ and $C_{i}$ are solute concentrations in the mobile and immobile regions, respectively; $\mathrm{S}_{\mathrm{e}}$ and $\mathrm{S}_{\mathrm{i}}$ are the respective sorbed concentrations, and $\square_{e}$ and $\square_{\mathrm{i}}$ are the volume fractions of the mobile and immobile liquid regions. This two-region model has five parameters: velocity (v), longitudinal dispersion $\left(D_{L}\right)$, equilibrium sorption $\left(K_{d}=S / C\right)$, diffusional mass transfer between mobile and immobile pore fluid $\left(\square_{\mathrm{e}}\right)$, and the fraction solute mass in the mobile region (f). The two-region model is mathematically equivalent to a fast and slow reaction in parallel or in series. In this study, the two-region model was fit to T17 tracer data because a poor fit of the equilibrium and first-order model indicated the presence of mobile-immobile pore fluid regions (i.e., heterogeneities). The two-region model was fit to T17 solute data fixing the longitudinal dispersivity and fraction of mobile pore fluid (f) at the tracer values.

The code CXTFIT contains analytical solutions to the equilibrium model (i.e., Equation [5.3]), the first-order model (Equations [5.4] and [5.5]), and the two-region model (Equations [5.7] and [5.8]). How well simulations of solute breakthrough with the equilibrium, first-order, and two-region models fit breakthrough data indicated whether the conceptual model was valid. In general a poor model fit indicated that the mathematical description of the physical and chemical processes was insufficient to describe the actual data. Progressively more complex models were used if simulations could not describe the breakthrough data, as indicated by the following scenarios:

(i) equilibrium model shows a good fit to both tracer and solute breakthrough data. This indicates an equilibrium sorption reaction $\left(\mathrm{K}_{\mathrm{d}}=\mathrm{S} / \mathrm{C}\right)$ was likely occurring.

(ii) equilibrium model fit to tracer data, but solute data has a poor fit with the equilibrium model and a good fit with the first-order model. This indicates equilibrium sorption of the solute was not occurring, and a reversible first-order kinetic model could represent the sorption/desorption rate occurring. 
(iii) equilibrium model fit to tracer data, but solute data has a poor fit with the equilibrium and first-order model and a good fit with the two-region model. This indicates equilibrium sorption and first-order reversible kinetic sorption was not occurring, but a more complex process(es) was occurring. 


\subsection{Results}

\subsection{Physical and Chemical Characteristics of Sediment Cores}

Table 6.1 summarizes the bulk fraction distribution of four sediment core samples taken adjacent to sediment cores (i.e., within 6 inches) used in the desorption experiments. Bulk fraction distributions in these cores were assumed to be the same as those used in the desorption experiments as visual examination of these cores' bulk fraction features showed no observable differences from those of the cores used in the desorption experiments. Core samples A and B, representing desorption experiments T15 and T17, had similar distributions with approximately 87 to $92 \%$ of the mass associated with the gravel and sand fractions. This is in contrast to core sample $\mathrm{C}$, representing desorption experiment T18, which contained a high sand content $(83.5 \%)$ and virtually no gravel. Among these three samples, sample $\mathrm{C}$ had the largest combined silt/clay content. Core sample D, representing desorption experiment T19, had a combined silt/clay content of $82.2 \%$ (36.7\% clay).

The organic carbon content of all four cores was low $(<0.1 \%)$ (Table 6.2). Core D contained the highest organic carbon content $(0.088 \%)$, while core samples A and C contained the lowest $(0.024 \%$ and $0.017 \%$, respectively). Core sample B contained the highest inorganic carbon content $(0.374 \%)$ possibly due to the presence of small amounts of calcium carbonate. Inorganic carbon was not detected in core samples A and C.

Table 6.1. Bulk Fraction (\%) Classification of Aquifer Samples

\begin{tabular}{|c|c|c|c|c|}
\hline Compositional Component & $\mathrm{A}^{(\mathrm{a})}(\mathrm{T} 15)$ & $\mathrm{B}^{(\mathrm{b})}(\mathrm{T} 17)$ & $\mathrm{C}^{(\mathrm{c})}(\mathrm{T} 18)$ & $\mathrm{D}^{\text {(d) }}(\mathrm{T} 19)$ \\
\hline Gravel & 57.5 & 66.5 & 1.88 & 8.21 \\
\hline Sand & 29.0 & 25.6 & 83.5 & 9.53 \\
\hline Silt & 10.2 & 6.02 & 10.2 & 45.5 \\
\hline Clay & 3.39 & 1.97 & 4.42 & 36.7 \\
\hline $\begin{array}{l}\text { (a) } 230 \text { to } 232 \text { feet. } \\
\text { (b) } 292 \text { to } 294 \text { feet. } \\
\text { (c) } 364 \text { to } 366 \text { feet. } \\
\text { (d) } 430 \text { to } 432 \text { feet. }\end{array}$ & & & & \\
\hline
\end{tabular}

Table 6.2. Carbon Analysis of Aquifer Core Samples

\begin{tabular}{||l|c|c|c||}
\hline \hline \multicolumn{1}{|c|}{ Experiment } & Total Carbon (\%) & Inorganic Carbon (\%) & Organic Carbon (\% by Difference) \\
\hline \hline A (T15) & 0.024 & 0.000 & 0.024 \\
\hline B (T17) & 0.433 & 0.374 & 0.059 \\
\hline C (T18) & 0.017 & 0.00 & 0.017 \\
\hline D (T19) & 0.123 & 0.036 & 0.088 \\
\hline
\end{tabular}


Core samples A and B had similar particle size distributions with only $35 \%$ to $40 \%$ of the mass in the 2 millimeters and lower particle diameter range. This is in contrast to core sample $\mathrm{C}$ where approximately $90 \%$ of the total mass could be accounted for in the 2 millimeter or lower size range. Nearly $100 \%$ of the mass of core sample D had particles in the 2 millimeters or less size range. Unlike the other samples, approximately $90 \%$ of the mass resided in particles of sizes of 250 micrometers or less (Figure 6.1).

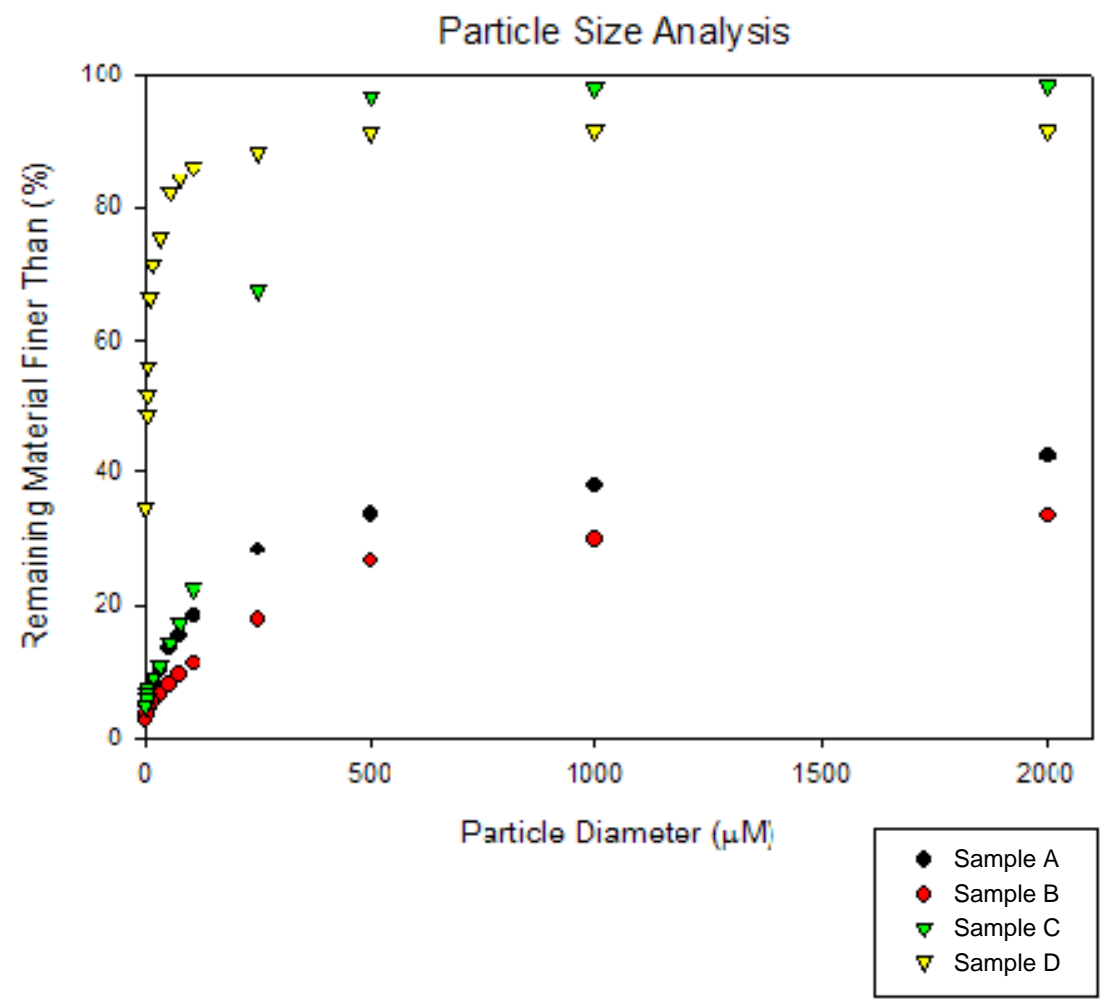

Figure 6.1. Particle Size Distribution in Aquifer Sediment Core Samples

\subsection{Desorption Experiments}

\subsection{1 $\mathrm{CCl}_{4}$ and $\mathrm{CCl}_{3}$ Behavior in Column Desorption Experiments}

$\mathrm{CCl}_{4}$ desorption profiles from the three sediment cores (Figure 6.2 and Appendix B for experiments $\mathrm{T} 15, \mathrm{~T} 17, \mathrm{~T} 18)$ were used to determine values of $\mathrm{K}_{\mathrm{d}}$. Integration of the breakthrough area for each $\mathrm{CCl}_{4}$ desorption profile resulted in calculated $\mathrm{K}_{\mathrm{d}}$ values of $0.11 \mathrm{~L} / \mathrm{kg}, 0.14 \mathrm{~L} / \mathrm{kg}$, and $0.37 \mathrm{~L} / \mathrm{kg}$, respectively (Table 6.3). Solvent extraction of the sediment cores following experiment completion revealed fractions of $11 \%$ (e.g., 1-0.889 x 100 in btc/total column of Table 6.3 ), $2 \%$, and $1 \%$ remaining with the sediment for cores $\mathrm{T} 15, \mathrm{~T} 17$, and $\mathrm{T} 18$, respectively (Table 6.3). There was no $\mathrm{CCl}_{4}$ detected in the aqueous effluent samples of sediment core T19 (data in Appendix B), although organic solvent extraction of the sediment core following the experiment removed 1 microgram of $\mathrm{CCl}_{4}$, or slightly less than the other three columns (Table 6.3). 

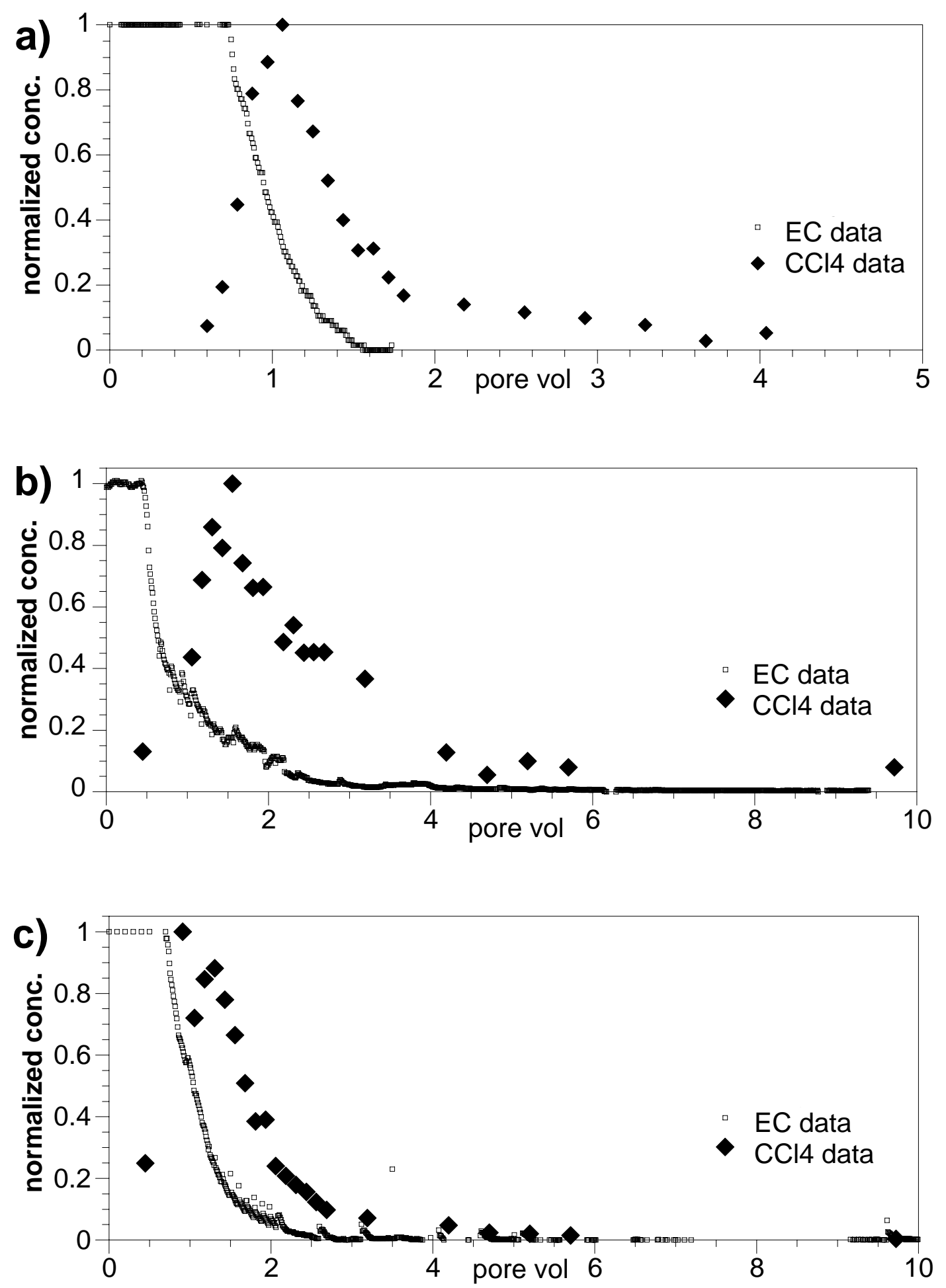

Figure 6.2. Tracer and Carbon Tetrachloride Breakthrough Data for Column Experiments T15 (a), T17 (b), and T18 (c) 
$\mathrm{CHCl}_{3}$ desorption profiles from sediment cores T17 and T18 (Figure 6.3 and Appendix B) with a 20 pore volume water injection were used to calculate $\mathrm{K}_{\mathrm{d}}$ values. Integration of the chloroform $\left(\mathrm{CHCl}_{3}\right)$ breakthrough areas resulted in calculated $\mathrm{K}_{\mathrm{d}}$ values of $0.43 \mathrm{~L} / \mathrm{kg}$ and $0.084 \mathrm{~L} / \mathrm{kg}$ for sediment cores $\mathrm{T} 17$ and T18, respectively (Table 6.3). No chloroform was detected in the effluent of sediment core $\mathrm{T} 19$ when subjected to aqueous desorption (detection limit $0.5 \mathrm{ppb}$ ). $\mathrm{CHCl}_{3}$ was not analyzed for in sediment core T15. Therefore, neither a desorption profile nor a value of $\mathrm{K}_{\mathrm{d}}$ was generated for this sample. Solvent extraction of the sediment cores following experiment completion revealed fractions of $70 \%$, and $61 \%$ remaining with the sediment for cores $\mathrm{T} 17$ and $\mathrm{T} 18$, respectively (Table 6.3 ).
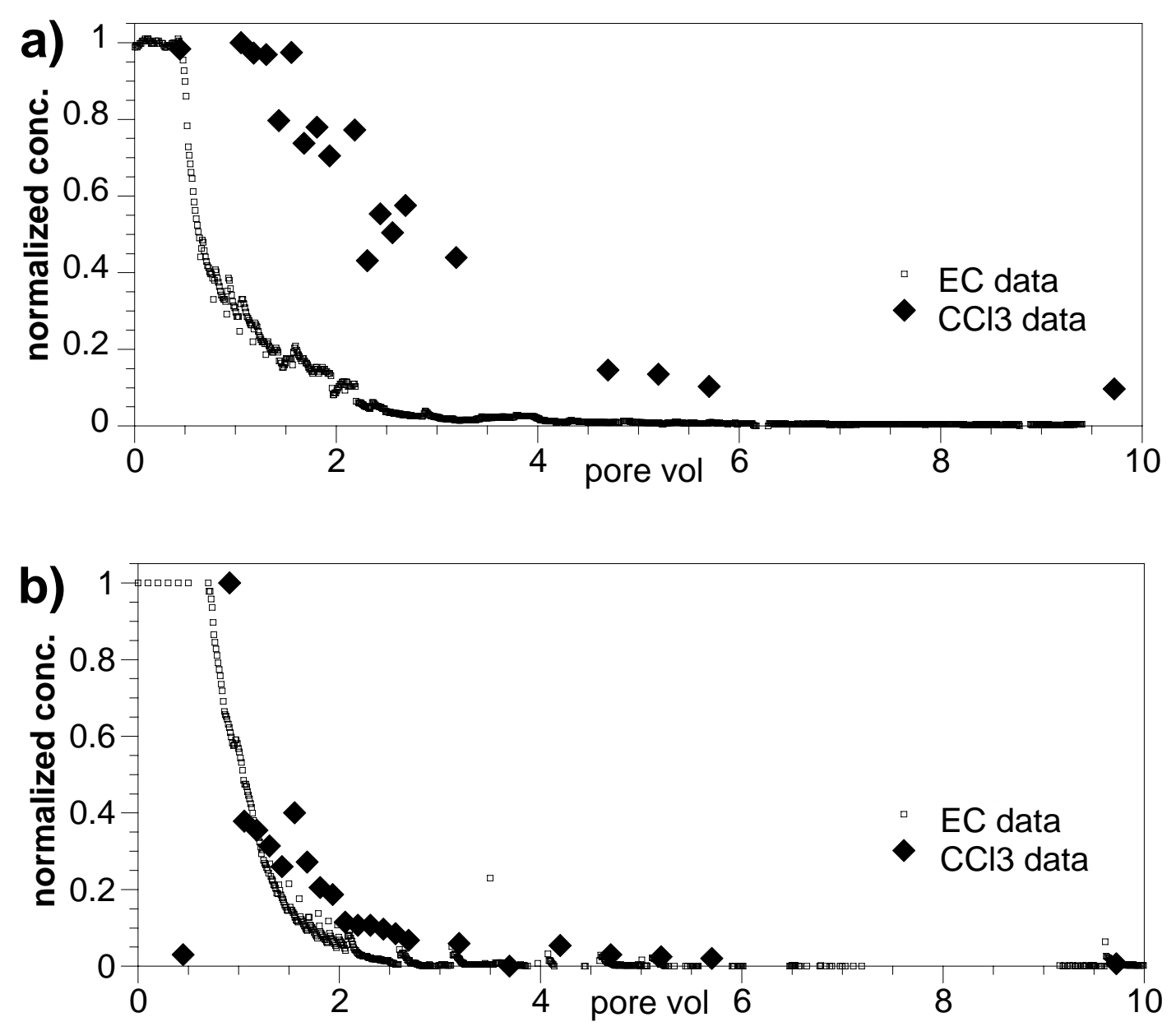

Figure 6.3. Tracer and Chloroform Breakthrough Data for Column Experiments T17 (a) and T18 (b) 
Table 6.3. Column Experiment Solute Mass Retardation and Mass Balance

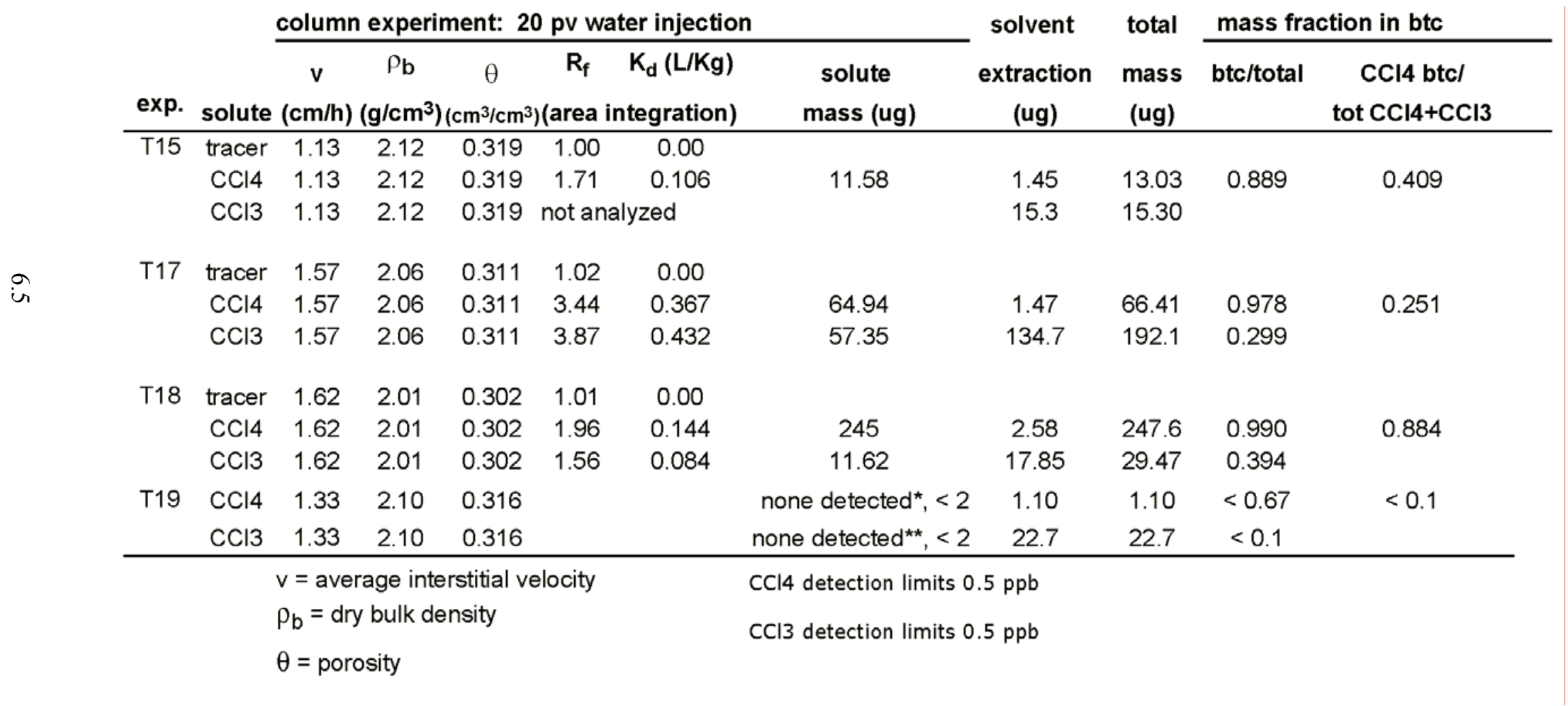




\subsubsection{Simulation of Tracer Behavior in 1-D Column Experiments}

Simulations were conducted to quantify physical and chemical kinetic processes that were occurring in the column experiments for the tracer (electrical conductivity) and solutes $\mathrm{CCl}_{4}$ and $\mathrm{CCl}_{3}$. These processes would produce breakthrough curve spreading that was greater than that described by longitudinal hydrodynamic dispersion (described in detail in Section 5). Tracer data was simulated first to define the longitudinal dispersion, then solute data was simulated using the tracer dispersivity value. Tracer desorption data and simulations for the three sediment core experiments (T15, T17, T18) are shown in Figure 6.4. Sediment cores T15 and T18 exhibited the least tailing (i.e., tracer equilibrium reached by 2.5 pore volumes), whereas sediment core T18 exhibited greater tailing (i.e., tracer equilibrium not reached by 5 pore volumes). Sediment core T15 was well fit by the equilibrium model with the simulated breakthrough area within $2 \%$ of the data breakthrough area (Figure 6.4a, Table 6.4). The tracer in soil column T18 behaved similarly to the tracer in experiment T15 (Figure 6.4c). The equilibrium model was able to simulate all but $2.5 \%$ of the column breakthrough area for sediment core T18 (Table 6.4, model/data under equilibrium model columns). The first-order model improved the fit of the T18 tracer profile slightly (i.e., all but $0.2 \%$ of the area accounted for, Figure $6.4 \mathrm{c}$ ). The two-region model fit to the core sample T17 tracer data was within $0.5 \%$ of the data breakthrough curve area (Table 6.4), whereas the equilibrium and first-order model fit breakthrough area was $19 \%$ smaller (i.e., did not fit the tailing, Figure 6.4b).

\subsubsection{Simulation of $\mathrm{CCl}_{4}$ Behavior in Column Desorption Experiments}

Simulations were conducted to approximate the $\mathrm{CCl}_{4}$ desorption profiles from the three sediment cores (T15, T17, T18) to quantify physical and chemical kinetic processes that were occurring. Equilibrium, first-order, and two-region models were used to fit the solute data using the tracer dispersivity for each respective experiment. Values for retardation factor (i.e., $\mathrm{K}_{\mathrm{d}}$ ) were initially set at the integrated value (Table 6.3) but allowed to vary in the simulation to obtain a slightly better fit. For the equilibrium model, $R_{f}$ was the only parameter that was fit by the parameter estimation routine. For the first-order model, $R_{f}$ and kb were fit. For the two-region model fits to experiment $T 15$ and $T 18, R_{f}, \alpha$, and $f$ were fit by the parameter estimation routine. The two-region model solute data fit to experiment T17 was different, as the tracer data exhibited clear immobile pore space. The two-region model was fit to the T17 tracer data to obtain both dispersivity and the fraction of mobile pore fluid (f). The T17 solute data was then fit with the two-region model using the tracer value for dispersivity and $\mathrm{f}$, allowing only $\mathrm{R}_{\mathrm{f}}$ and $\alpha$ to be fit by the parameter estimation routine.

The shape of the $\mathrm{CCl}_{4}$ desorption profile for sediment core $\mathrm{T} 15$ indicated the presence of tailing that was not present in the profile of the tracer for the same core. Simulation of the T15 $\mathrm{CCl}_{4}$ breakthrough showed that the two-region model could account for the tailing (Figure 6.5a, simulated/actual breakthrough mass $=1.03$, Table 6.4), whereas the equilibrium and first-order models did not account for the tailing and breakthrough mass was $30 \%$ less than the observed mass. Parameters used in simulations are in Table 6.4. 
Table 6.4. Column Experiment Simulation Results

\begin{tabular}{|c|c|c|c|c|c|c|c|c|c|c|c|c|c|c|c|c|c|c|c|c|c|c|}
\hline \multirow[b]{3}{*}{ exp. } & \multirow[b]{3}{*}{ solute } & \multirow{3}{*}{$\begin{array}{c}v \\
(\mathrm{~cm} / \mathrm{h})\end{array}$} & \multicolumn{5}{|c|}{ |-----.-- equilibrium model --------- | } & \multicolumn{7}{|c|}{ - first-order model } & \\
\hline & & & $\mathbf{R}_{\mathrm{f}}$ & $\mathrm{K}_{\mathrm{d}}$ & D & ssq & model & $\mathbf{R}_{\mathrm{f}}$ & Kd & D & kb & half-life & ssq & model/ & $\mathbf{R}_{\mathrm{f}}$ & Kd & D & $\alpha$ & half-life & f, mobile & ssq & model/ \\
\hline & & & & $(\mathrm{L} / \mathrm{Kg})$ & $(\mathrm{cm} 2 / \mathrm{s})$ & & data & & $(\mathrm{L} / \mathrm{Kg})$ & $(\mathrm{cm} 2 / \mathrm{s})$ & $(1 / \mathrm{h})$ & (h) & & data & & $(\mathrm{L} / \mathrm{Kg})$ & (cm2/s) & $(1 / h)$ & (h) & fraction & & data \\
\hline \multirow[t]{2}{*}{ T15 } & tracer & 1.13 & $1.0 \mathrm{~F}$ & 0.00 & $1.57 \mathrm{E}-03$ & 0.080 & 1.025 & & & & & & & & & & & & & & & \\
\hline & $\mathrm{CCl} 4$ & 1.13 & 1.26 & 0.039 & $1.57 \mathrm{E}-3 \mathrm{~F}$ & 0.390 & 0.696 & 1.27 & 0.041 & $1.57 \mathrm{E}-3 \mathrm{~F}$ & 10.565 & 0.0656 & 0.394 & 0.669 & $1.7 \mathrm{~F}$ & 0.105 & $1.57 \mathrm{E}-3 \mathrm{~F}$ & 4.87E-04 & 1422 & 0.455 & 0.036 & 1.032 \\
\hline \multirow[t]{3}{*}{ T17 } & tracer & 1.57 & $1.0 \mathrm{~F}$ & 0.00 & 3.33E-03 & 0.194 & 0.814 & 1.14 & 0.021 & 3.33E3F & $7 \mathrm{E}-08$ & $9 \mathrm{E}+06$ & 0.203 & 0.825 & 1.22 & 0.105 & 3.33E3F & $2.44 \mathrm{E}-02$ & 28.409 & 0.355 & 0.006 & 0.995 \\
\hline & $\mathrm{CCl} 4$ & 1.57 & 2.23 & 0.185 & $3.33 \mathrm{E}-3 \mathrm{~F}$ & 0.372 & 0.491 & 2.41 & 0.212 & 3.33E3F & 0.1617 & 4.2867 & 0.316 & 0.653 & 2.73 & 0.261 & 3.33E3F & $2.38 \mathrm{E}-02$ & 29.176 & $0.355 \mathrm{~F}$ & 0.263 & 0.824 \\
\hline & $\mathrm{CCl} 3$ & 1.57 & 2.94 & 0.292 & 3.33E-3F & 0.852 & 0.704 & 3.37 & 0.357 & 3.33E3F & 0.1979 & 3.502 & 0.726 & 0.948 & 3.34 & 0.353 & 3.33E3F & $2.38 \mathrm{E}-02$ & 29.136 & $0.355 \mathrm{~F}$ & 0.547 & 0.962 \\
\hline \multirow[t]{5}{*}{ T18 } & tracer & 1.62 & $1.0 \mathrm{~F}$ & 0.00 & $3.00 \mathrm{E}-03$ & 0.035 & 0.974 & 1.10 & 0.015 & $3.00 \mathrm{E}-3 \mathrm{~F}$ & 0.1704 & 4.07 & 0.0275 & 1.002 & & & & & & & & \\
\hline & $\mathrm{CCl} 4$ & 1.62 & 1.73 & 0.110 & $3.00 \mathrm{E}-3 \mathrm{~F}$ & 0.025 & 0.849 & 1.73 & 0.110 & $3.00 \mathrm{E}-3 \mathrm{~F}$ & 11.073 & 0.0626 & 0.0262 & 0.852 & 1.73 & 0.110 & $1.57 \mathrm{E}-3 \mathrm{~F}$ & $1.68 \mathrm{E}-04$ & 4120.2 & 0.002 & 0.025 & 0.851 \\
\hline & $\mathrm{CCl} 3$ & 1.62 & 1.25 & 0.038 & $3.00 \mathrm{E}-3 \mathrm{~F}$ & 0.191 & 0.658 & 1.33 & 0.050 & $3.00 \mathrm{E}-3 \mathrm{~F}$ & 0.0972 & 7.13 & 0.129 & 0.838 & 1.45 & 0.068 & $1.57 \mathrm{E}-3 \mathrm{~F}$ & $5.92 \mathrm{E}-03$ & 117.11 & 0.347 & 0.112 & 1.027 \\
\hline & $v=a v e r$ & ntersti & veloci & & $\mathrm{D}=$ hydrody & ynamic & & & & model/dat & $\mathrm{ta}=1$ & btc ar & & & & & gration & & & & & \\
\hline & $\rho_{b}=d r y b$ & density & & & $\theta=$ porosity & & & & & $\mathrm{F}=$ param & neter fi> & ed in simu & lation & & & & & & & & & \\
\hline
\end{tabular}



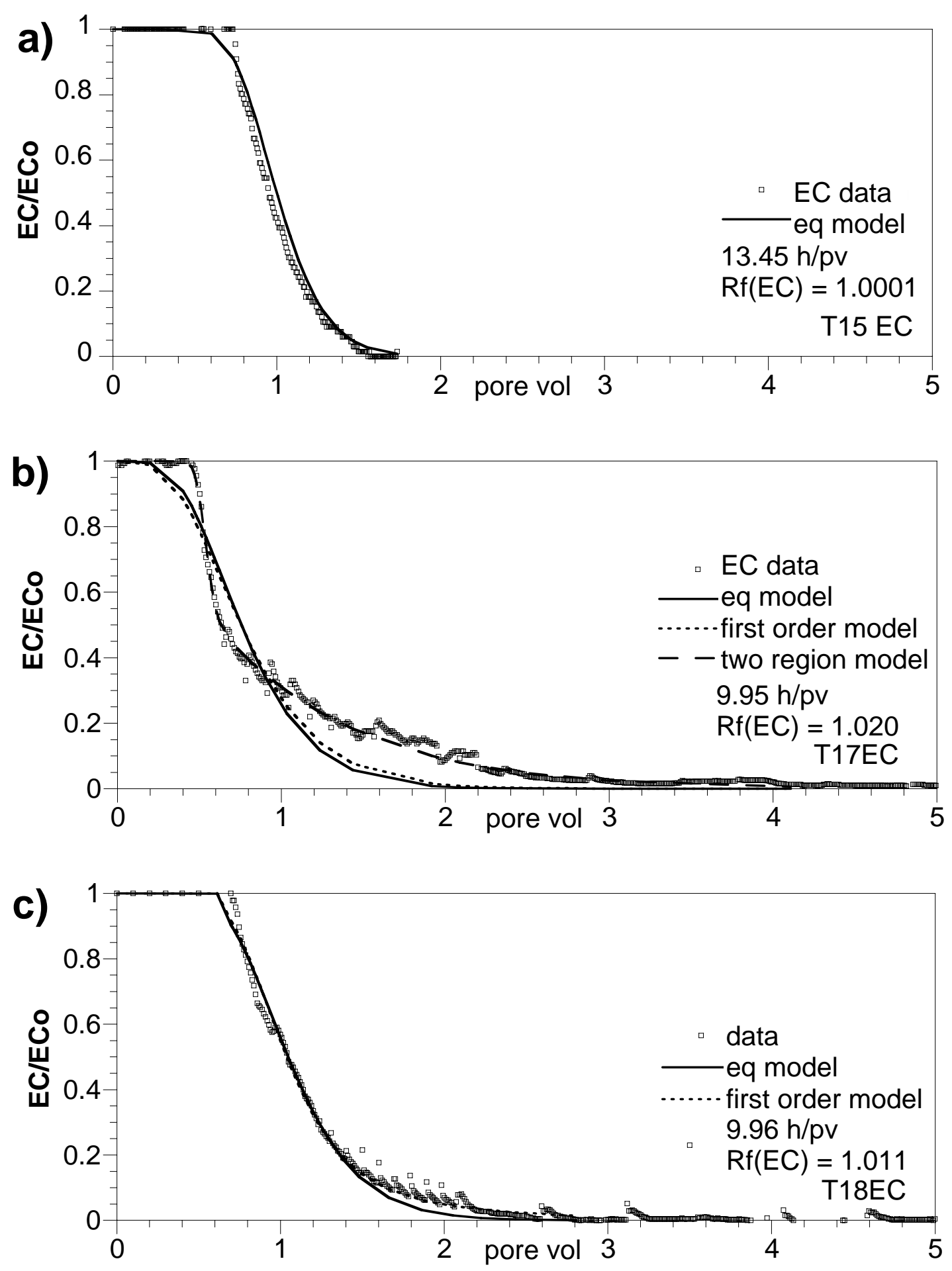

Figure 6.4. Conservative Tracer Breakthrough Data for Column Experiments T15 (a), T17 (b), and T18 (c) 

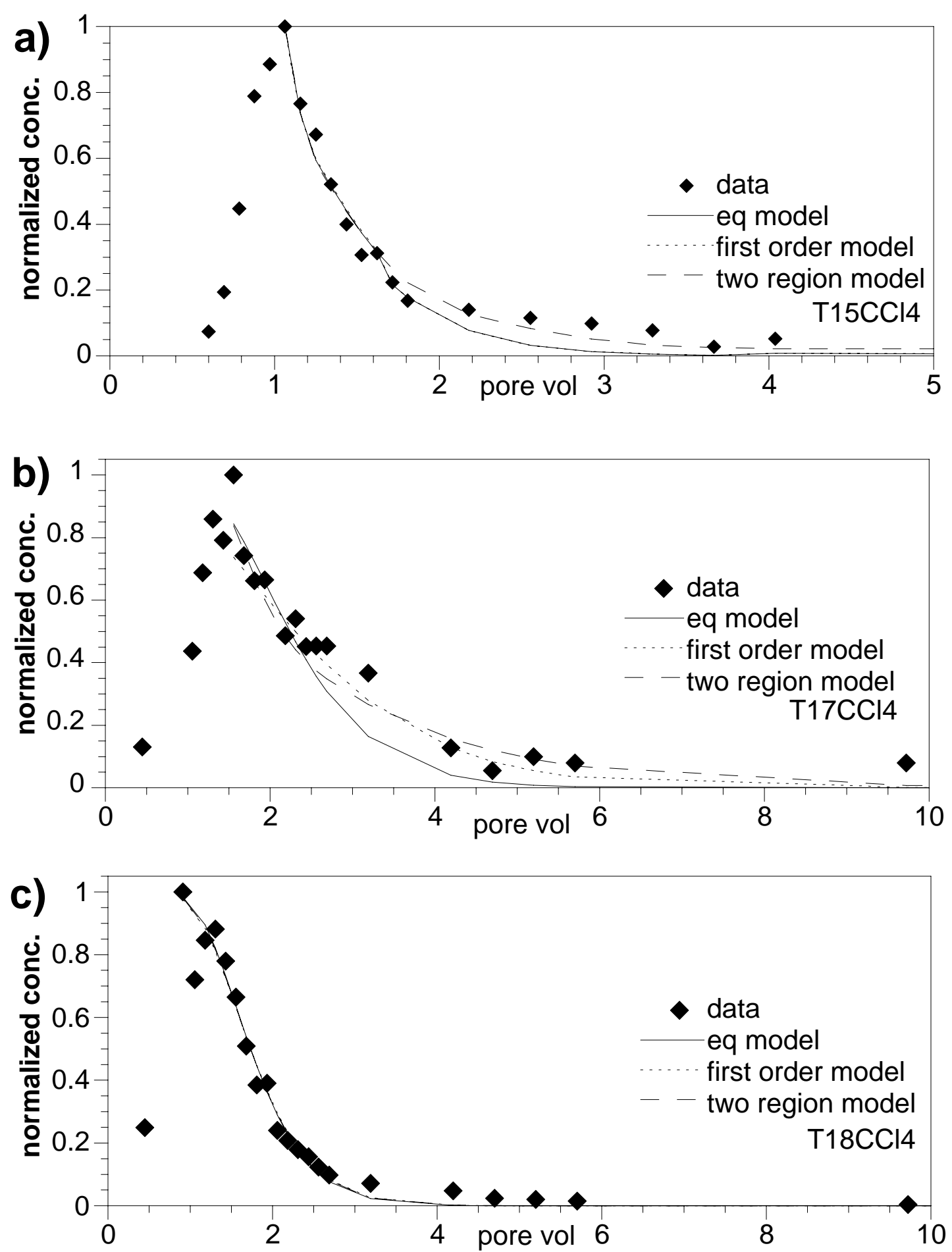

Figure 6.5. Carbon Tetrachloride Breakthrough Data for Column Experiments T15 (a), T17 (b), and T18 (c) 
The $\mathrm{CCl}_{4}$ desorption profile for sediment core $\mathrm{T} 17$ showed increased tailing relative to the tracer from the same core. $\mathrm{CCl}_{4}$ tailing extended the entire 17 pore volumes, as compared with tailing to 2.5 pore volumes for the tracer. Simulation of the $\mathrm{T} 17 \mathrm{CCl}_{4}$ breakthrough showed that the equilibrium model could only account for $49 \%$ of the breakthrough curve area, the first-order model only $65 \%$, and the two region model $82 \%$. The two-region model fit the general shape of the desorption profile (Figure $6.5 \mathrm{~b}$ ). Core T17 contained the highest inorganic and organic carbon content of the three cores, suggesting that the increased tailing $\left(\mathrm{CCl}_{4}\right.$ resistance to desorption) may be related to these factor differences.

Simulation of $\mathrm{CCl}_{4}$ breakthrough for sediment core T18 was well fit by the equilibrium model, and the first-order and/or two-region models had the same fit.

\subsubsection{Simulation of Chloroform Behavior in Column Desorption Experiments}

The shape of the $\mathrm{CHCl}_{3}$ desorption profiles for sediment cores $\mathrm{T} 17$ and $\mathrm{T} 18$ (Figure 6.6) exhibited similar tailing behavior, relative to the corresponding tracer profile as $\mathrm{CCl}_{4}$. Integration of the $\mathrm{CHCl}_{3}$ breakthrough areas resulted in calculated $\mathrm{K}_{\mathrm{d}}$ values of $0.43 \mathrm{~L} / \mathrm{kg}$ and $0.084 \mathrm{~L} / \mathrm{kg}$ for sediment cores $\mathrm{T} 17$ and T18, respectively. The equilibrium model provided poor fits for the T17 and T18 sediment core $\mathrm{CHCl}_{3}$ profiles (i.e., $70 \%$ and $66 \%$ of the areas accommodated, respectively, Table 6.4). Fit improved when the first-order model was used, however, the two-region model was needed to effectively describe both profiles. The two-region model was able to accommodate all but $4 \%$ and $3 \%$ of the areas of the breakthrough data for sediment cores T17 and T18, respectively. Parameters used in simulations are in Table 6.4.

\subsection{Carbon Tetrachloride and Chloroform Residuals in Sediment Cores}

Solvent extraction of each of the four sediment cores was performed following aqueous desorption, and the distribution of mass between desorption effluent and sediment was determined (Table 6.4). The mass associated with the sediment includes the small amount of solute in water in contact with the sediment following desorption. Greater than $89 \%$ of the $\mathrm{CCl}_{4}$ was found to be associated with the column effluent for sediment cores T15, T17, and T18. While low, all the $\mathrm{CCl}_{4}$ mass in sediment core $\mathrm{T} 19$ was associated with the sediment. In contrast, a significant portion of $\mathrm{CHCl}_{3}$ was found to be associated with the sediment. Residual $\mathrm{CHCl}_{3}$ mass associated with sediment core $\mathrm{T} 17$ was $70 \%$. For sediment core $\mathrm{T} 18$, residual mass was $61 \%$.

\subsection{Initial Sediment Core Solute Concentrations}

Initial concentrations of $\mathrm{CCl}_{4}$ and $\mathrm{CHCl}_{3}$ in experimental sediment cores were determined from sediment core masses and solvent extracted solute mass. These results are summarized in Table 6.5. Observed concentrations of $\mathrm{CCl}_{4}$ ranged from 0.5 to $121.7 \mu \mathrm{g} / \mathrm{kg}$ while $\mathrm{CHCl}_{3}$ concentrations ranged from 10.7 to $92.1 \mu \mathrm{g} / \mathrm{kg}$. Very little, if any, $\mathrm{CCl}_{4}$ was determined to be present on the sediment of core T19. 

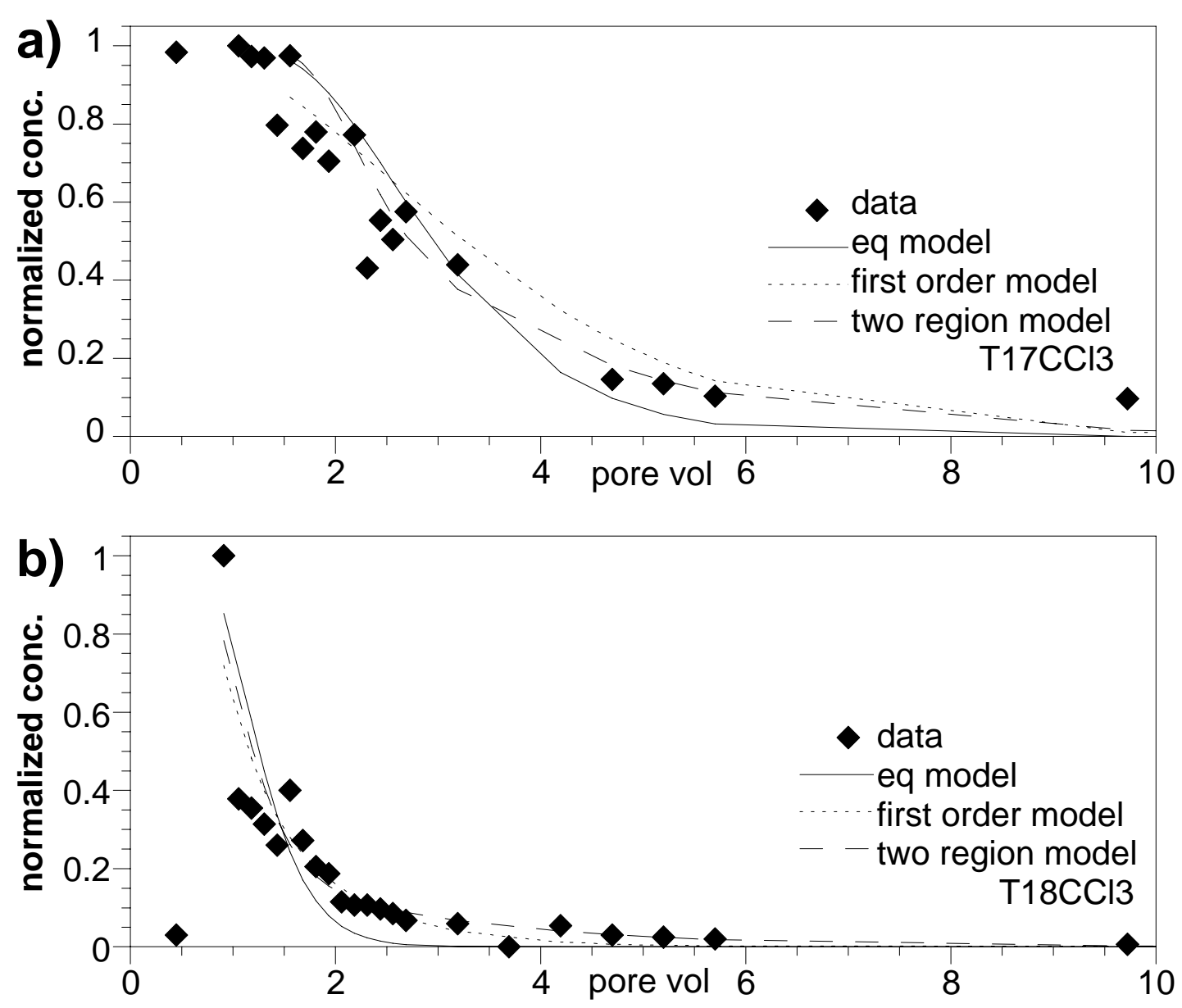

Figure 6.6. Chloroform Breakthrough Data for Column Experiments T17 (a) and T18 (b) Carbon Tetrachloride and Chloroform Residuals in Sediment Cores

Table 6.5. Initial Concentrations of $\mathrm{CCl}_{4}$ and $\mathrm{CHCl}_{3}$ in Sediment Cores

\begin{tabular}{||l|l|c|c|c||}
\hline \multicolumn{1}{|c|}{ Sediment Core } & \multicolumn{1}{|c|}{ Solute } & $\begin{array}{c}\text { Sediment Mass } \\
(\mathrm{kg})\end{array}$ & ${\text { Total Mass }(\mu \mathrm{g})^{(\mathrm{a})}}$ & $\begin{array}{c}\text { Sediment } \\
\text { Concentration } \\
(\mu \mathrm{g} / \mathrm{kg})^{(\mathrm{b})}\end{array}$ \\
\hline \hline $\mathrm{T} 15$ & $\mathrm{CCl}_{4}$ & 2.143 & 13.03 & 6.1 \\
\hline $\mathrm{T} 17$ & $\mathrm{CCl}_{4}$ & 2.086 & 66.41 & 31.8 \\
\hline $\mathrm{T} 18$ & $\mathrm{CHCl}_{3}$ & 2.086 & 192.1 & 92.1 \\
\hline & $\mathrm{CCl}_{4}$ & 2.034 & 247.6 & 121.7 \\
\hline $\mathrm{T} 19$ & $\mathrm{CHCl}_{3}$ & 2.034 & 29.47 & 14.5 \\
\hline \multicolumn{2}{|l|}{$\begin{array}{l}\text { (a) Total column effluent solute mass plus solvent extracted solute mass (Table 6.3). } \\
\text { (b) Wet weight. }\end{array}$} \\
\hline
\end{tabular}




\subsection{Concentrations of Solutes in Samples of Groundwater Collected at Sediment Depth Locations}

Table 6.6 summarizes the results of analysis of groundwater samples from well 299-W15-46 at those depths where sediment samples were collected for column desorption. The table includes results obtained from the Fluor Hanford, Inc. field laboratory and PNNL's fixed analytical laboratory. Good agreement was observed on the results from separate samples collected from the same depth. $\mathrm{CCl}_{4}$ concentrations ranged from 825 to $2,463 \mathrm{ppb}$ at an aquifer depth ranging from 71.6 to 111 meters ( 235 to 365 feet). Chloroform concentrations ranged from 37 to $400 \mathrm{ppb}$ over the same depth range. Trichloroethene was detected at concentration levels in the 2 to $10 \mathrm{ppb}$ range. The highest concentration, for all three compounds was observed at a depth of 89 to 89.6 meters (292 to 294 feet). We were unable to obtain a representative groundwater sample from a depth of 70 to 70.7 meters ( 230 to 232 feet) for analysis. For the purpose of the column desorption experiment on the sediment core from 70 to 70.7 meters (230 to 232 feet), it was assumed that the solute concentrations in the groundwater at 71.6 meters (235 feet) was the same as at a depth of 70 to 70.7 meters (230 to 232 feet). A groundwater sample could not be obtained from a depth of 131 to 131.7 meters (430 to 432 feet) because of the nature of the formation (i.e., Lower Ringold Mud-confining layer that separates the unconfined aquifer from the upper confined aquifer at this location).

Table 6.6. Summary of Groundwater Solute Data. Solute Concentration in $\mu \mathrm{g} / \mathrm{L}$

\begin{tabular}{|c|c|c|c|}
\hline $\begin{array}{l}\text { Groundwater Depth } \\
\text { meters(feet) }\end{array}$ & Carbon Tetrachloride & Chloroform & Trichloroethene \\
\hline $70-70.7(230-232)$ & $\mathrm{ND}^{(\mathrm{a})}$ & $\mathrm{ND}^{(\mathrm{a})}$ & $\mathrm{ND}^{(\mathrm{a})}$ \\
\hline $71.6(235)^{(\mathrm{b})}$ & 2,239 & 37 & 6.7 \\
\hline $81.7(268)^{(\mathrm{c})}$ & 825 & 43 & 10 \\
\hline $89-89.6(292-294)^{(\mathrm{d})}$ & $2,463 \pm 50(n=3)$ & $400 \pm 10(n=3)$ & $8 \pm 0.4(n=3)$ \\
\hline $111-111.6(364-366)^{(\mathrm{e})}$ & $1,145 \pm 20(n=3)$ & $123 \pm 5(n=3)$ & $2 \pm 2(n=3)$ \\
\hline $131-131.7(430-432)$ & $\mathrm{ND}^{(\mathrm{f})}$ & $\mathrm{ND}^{(\mathrm{f})}$ & $\mathrm{ND}^{(\mathrm{f})}$ \\
\hline \multicolumn{4}{|c|}{$\begin{array}{l}\text { (a) Method of groundwater collection at this depth (bailer) precluded collection of suitable groundwater samples } \\
\text { (b) Results from Fluor Hanford, Inc. field laboratory analysis. } \\
\text { (c) Results from Fluor Hanford, Inc. field laboratory analysis. PNNL analysis of groundwater from same depth } \\
\text { measured a CCl } \mathrm{Cl}_{4} \text { concentration of } 795 \mu \mathrm{g} / \mathrm{L} \text {. } \\
\text { (d) Fluor Hanford, Inc. field laboratory analysis results were } 2,918 \mu \mathrm{g} / \mathrm{L} \text { (carbon tetrachloride), } 413 \mu \mathrm{g} / \mathrm{L} \\
\text { (chloroform), and } 11.0 \mu \mathrm{g} / \mathrm{L} \text { (trichloroethene). } \\
\text { (e) Fluor Hanford, Inc. field laboratory analysis results were } 1,174 \mu \mathrm{g} / \mathrm{L} \text { (carbon tetrachloride), } 152 \mu \mathrm{g} / \mathrm{L} \\
\text { (chloroform), and } 7.2 \mu \mathrm{g} / \mathrm{L} \text { (trichloroethene). } \\
\text { (f) No data. }\end{array}$} \\
\hline
\end{tabular}

\subsection{Predicted Versus Observed $K_{d}$ Values}

Partition coefficient values from this study (Table 6.3) were compared to those predicted from equations that calculate values of $\mathrm{K}_{d}$ based on sediment organic fraction $\left(\mathrm{f}_{\mathrm{oc}}\right)$ and estimates of the normalized sorption coefficient $\left(\mathrm{K}_{\mathrm{oc}}\right)$ (Truex et al. 2001) (Table 6.7). Observed $\mathrm{CCl}_{4} \mathrm{~K}_{\mathrm{d}}$ values (this 
Table 6.7. Predicted Versus Observed $\mathrm{K}_{\mathrm{d}}$ Values

\begin{tabular}{|c|c|c|c|c|c|c|c|c|c|c|}
\hline Core & Solute & $\begin{array}{c}\mathrm{K}_{\mathrm{d}} \\
\text { (observed) }^{(\mathrm{a})} \\
\end{array}$ & $\begin{array}{c}\mathrm{OC} \\
(\%)^{(b)} \\
\end{array}$ & $\mathrm{f}_{\mathrm{oc}}$ & $\begin{array}{c}\mathrm{K}_{\mathrm{oc}} \\
(\mathrm{eq3})^{(\mathrm{cc})}\end{array}$ & $\mathrm{K}_{\mathrm{d}}$ (eq3) & $\begin{array}{c}\mathrm{K}_{\mathrm{d}(\text { obser })} \\
\mathrm{K}_{\mathrm{d}(\mathrm{Cal})} \\
\end{array}$ & $\begin{array}{c}\mathrm{K}_{\mathrm{oc}} \\
(\mathrm{eq} 4)^{(\mathrm{c})}\end{array}$ & $\mathrm{K}_{\mathrm{d}}$ (eq4) & $\begin{array}{c}\mathrm{K}_{\mathrm{d}(\mathrm{obser})} \\
\mathrm{K}_{\mathrm{d}(\mathrm{Cal})} \\
\end{array}$ \\
\hline$\overline{\mathrm{T}-15}$ & 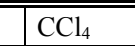 & 0.106 & 0.024 & 0.00024 & 1110.48 & $=0.0265$ & 4 & "161.11 & 0.0387 & 2.7 \\
\hline \multirow[t]{2}{*}{$\mathrm{T}-17$} & $\mathrm{CCl}_{4}$ & 0.367 & 0.059 & 0.00059 & 110.48 & 0.0651 & 5.6 & 161.11 & 0.0951 & 3.9 \\
\hline & $\mathrm{CHCl}_{3}$ & 0.432 & 0.059 & 0.00059 & 30.72 & 0.0181 & 23.9 & 38.26 & 0.0226 & 19.1 \\
\hline \multirow[t]{2}{*}{$\mathrm{T}-18$} & $\mathrm{CCl}_{4}$ & 0.144 & 0.017 & 0.00017 & 110.48 & 0.0188 & 7.6 & 161.11 & 0.0274 & 5.3 \\
\hline & $\mathrm{CHCl}_{3}$ & 0.084 & 0.017 & 0.00017 & 30.72 & 0.0052 & 16.8 & 38.26 & 0.0065 & 12 \\
\hline $\begin{array}{l}\text { (a) } \\
\text { (b) } \\
\text { (c) }\end{array}$ & $\begin{array}{l}\text { From Table } \\
\text { From Table } \\
\text { From Table } \\
(\mathrm{mg} / \mathrm{L}) . \text { Eq }\end{array}$ & $\begin{array}{l}3, \text { this study. } \\
2 \text {. } \\
\text { of Truex et al } \\
\text { tion } 4: \log (\mathrm{K}\end{array}$ & 01. & ion 3: 1 & 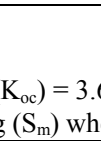 & -0.55 & (S) whe & $\begin{array}{l}\text { the w } \\
\text { ubility }\end{array}$ & solubilit & $\begin{array}{l}\text { the solute } \\
\mathrm{nol} / \mathrm{L}) \text {. }\end{array}$ \\
\hline
\end{tabular}

study) were 3 to 8 times higher than predicted depending on which of the two equations were applied. Observed $\mathrm{CHCl}_{3} \mathrm{~K}_{\mathrm{d}}$ values (this study) were 12 to 24 times higher than predicted depending on which of the two equations were applied.

\subsection{Predicted Versus Observed Sediment Core Solute Concentrations}

Groundwater concentrations of $\mathrm{CCl}_{4}$ and $\mathrm{CHCl}_{3}$ (Table 6.6) and the corresponding experimentally determined partition coefficients for three of the sediment core experiments (Table 6.3) were used to predict solute concentrations in the corresponding sediments assuming equilibrium existed between groundwater and sediment. These concentrations were compared to the initial solute concentrations observed to be present in the sediment cores. The results are summarized in Table 6.8. Predicted concentrations of $\mathrm{CCl}_{4}$ were significantly higher than observed in the three sediment cores, particularly sediment cores T15 and T17. In these two cores, observed concentrations were $2.8 \%$ and $3.5 \%$ of predicted values, respectively. The observed concentration of $\mathrm{CCl}_{4}$ in sediment core $\mathrm{T} 18$ was $73.8 \%$ of the predicted value. The observed $\mathrm{CHCl}_{3}$ concentration in soil core $\mathrm{T} 17$ was $53.2 \%$ of that predicted whereas the predicted $\mathrm{CHCl}_{3}$ concentration was closer to the concentration observed in sediment core T18. Since $\mathrm{K}_{\mathrm{d}}$ values were not determined for sediment core T19, a comparison could not be made for that sample.

Table 6.8. Predicted Versus Observed Sediment Solute Concentrations

\begin{tabular}{||l|l|c|c|c|c||}
\hline \hline Experiment & \multicolumn{1}{|c|}{ Compound } & $\mathrm{K}_{\mathrm{d}}(\mathrm{L} / \mathrm{kg})$ & $\begin{array}{c}\text { Groundwater } \\
\text { Concentration } \\
(\mu \mathrm{g} / \mathrm{L})\end{array}$ & $\begin{array}{c}\text { Predicted } \\
\text { Sediment } \\
\text { Concentration } \\
(\mu \mathrm{g} / \mathrm{kg})\end{array}$ & $\begin{array}{c}\text { Observed } \\
\text { Sediment } \\
\text { Concentration } \\
(\mu \mathrm{g} / \mathrm{kg})\end{array}$ \\
\hline \hline $\mathrm{T} 15$ & $\mathrm{CCl}_{4}$ & 0.106 & 2,239 & 237 & 6.1 \\
\hline $\mathrm{T} 17$ & $\mathrm{CCl}_{4}$ & 0.367 & 2,463 & 904 & 31.8 \\
\hline $\mathrm{T} 18$ & $\mathrm{CHCl}_{3}$ & 0.432 & 400 & 173 & 92.1 \\
\hline & $\mathrm{CCl}_{4}$ & 0.144 & 1,145 & 165 & 121.7 \\
\hline $\mathrm{T} 19$ & $\mathrm{CHCl}_{3}$ & 0.084 & 123 & 10 & 14.5 \\
\hline & $\mathrm{CCl}_{4}$ & & & & 0.5 \\
\hline & $\mathrm{CHCl}_{3}$ & & & & 10.7 \\
\hline
\end{tabular}




\subsection{Discussion}

Intact sediment cores were collected from borehole 299-W15-46 located adjacent to the 216-Z-9 trench at the Hanford Site's 200 West Area. Four split spoon samples were collected at unconfined aquifer depths of 70 to 70.7 meters ( 230 to 232 feet), 89 to 89.6 meters (292 to 294 feet), 111 to 111.6 meters ( 364 to 366 feet) and 131 to 131.7 meters ( 430 to 432 feet), respectively. The borehole was drilled into the $\mathrm{CCl}_{4}$ plume at a location where groundwater concentration of $\mathrm{CCl}_{4}$ concentration was anticipated to be in the range of 1 to 2 parts per million. Therefore, it was also anticipated that the collected aquifer sediments would be contaminated with $\mathrm{CCl}_{4}, \mathrm{CCl}_{4}$ degradation products and perhaps other solute compounds. Solute contaminants identified would have been in contact with these sediments for at least 30 years when discharges to the trench had ceased (DOE 2001). The nature of these sediments afforded an opportunity to perform aqueous desorption experiments to assess the effects of long contact time on organic solute transport in aquifer sediments. Such experiments are not easily simulated in the laboratory where contact times are limited as a result of concern over the ability to control degradation processes. Sediment cores from each of the disassembled split spoon samplers were brought back to the laboratory. Aqueous desorption experiments were performed on these samples within a few days of their arrival at the laboratory to ensure sample quality and stability.

Chemical analysis of sediment cores from each depth showed the presence of the organic solutes $\mathrm{CCl}_{4}, \mathrm{CHCl}_{3}$, methylene chloride, and trichloroethene. Chemical analysis of column effluent samples for methylene chloride was confounded by suspect sample contamination. Concentrations of trichloroethene in column effluent were near the analytical limit. Therefore, desorption profile data collection was limited to $\mathrm{CCl}_{4}$ and $\mathrm{CHCl}_{3}$.

Area integration of tracer/solute curves (profiles) was used to calculate partition coefficients, taking into account any dispersivity effects identified from the conductivity profiles. $\mathrm{CCl}_{4} \mathrm{~K}_{\mathrm{d}}$ values were in the range 0.106 to $0.367 \mathrm{~L} / \mathrm{kg}$, in which the sediment organic carbon contents were less than $0.1 \%(0.017$ to $0.059 \%$ ). For the two sediments where $\mathrm{CHCl}_{3}$ was measured, $\mathrm{CHCl}_{3} \mathrm{~K}_{\mathrm{d}}$ values were $0.432 \mathrm{~L} / \mathrm{kg}$ and $0.084 \mathrm{~L} / \mathrm{kg}$, respectively. Previously, Truex et al. (2001) estimated the $\mathrm{K}_{\mathrm{d}}$ (based on $\mathrm{K}_{\mathrm{oc}}$ ) for $\mathrm{CCl}_{4}$ in a Hanford soil with an averaged organic carbon content of $0.2 \%$. The $\mathrm{K}_{\mathrm{d}}$ was estimated to be in the range of 0.016 to $0.83 \mathrm{~L} / \mathrm{kg}$ with a most probable value in this range of $0.12 \mathrm{~L} / \mathrm{kg}$ (Truex et al. 2001); on the low end of the range of values calculated in this study. The best estimate value of Truex et al. 2001 would be $0.06 \mathrm{~L} / \mathrm{kg}$ based on a $0.1 \%$ sediment organic carbon content.

At levels of organic carbon above $0.1 \%, \mathrm{~K}_{\mathrm{oc}}$ can be used to estimate the $\mathrm{K}_{\mathrm{d}}$ of an organic compound if the organic carbon content of the sediment is known. Past research suggests that application of this relationship to sediments with organic carbon content below $0.1 \%$ (e.g., at Hanford) may under-predict sorption in sediment. For example, a $\mathrm{CCl}_{4} \mathrm{~K}_{\mathrm{d}}$ value of $0.39 \mathrm{ml} / \mathrm{g}$ was reported for a soil with an organic carbon content of less than $0.03 \%$ (Zhao et al. 1999). In contrast, the predicted $\mathrm{K}_{\mathrm{d}}$ (based on $\mathrm{K}_{\mathrm{oc}}$ ) for $\mathrm{CCl}_{4}$ in a soil with an organic carbon content of $0.03 \%$ was shown to range from 0.015 to $0.081 \mathrm{ml} / \mathrm{g}$ (Truex et al. 2001). Values of $\mathrm{CCl}_{4}$ and $\mathrm{CHCl}_{3}$ partition coefficients from this study support these earlier observations, where $\mathrm{CCl}_{4}$ and $\mathrm{CHCl}_{3} \mathrm{~K}_{\mathrm{d}}$ 's from this study were 3-8 and 12-23 times larger than would be 
predicted based on sediment organic carbon content, so may be sorbing to mineral surfaces such as clays and iron oxides.

The significant differences between observed versus predicted (i.e., lower) concentrations of $\mathrm{CCl}_{4}$ in sediment cores (e.g., T15 and T17; Table 6.8) suggest the occurrence of $\mathrm{CCl}_{4}$ degradation in these sediments. $\mathrm{CHCl}_{3}$ can be produced by abiotic dechlorination of $\mathrm{CCl}_{4}$ by a reductant such as adsorbed ferrous iron on an iron oxide on 2:1 smectite clay (Amonette et al. 2000). $\mathrm{CCl}_{4}$ appeared to show little affinity for sediment as demonstrated by most of the $\mathrm{CCl}_{4}$ in the desorption experiments to be associated with the aqueous effluent streams (i.e., 89 to $99 \%$ ). Evidence for the presence of contaminant resistant fractions in soils and sediments for a wide range of organic contaminants has been summarized in past reviews (Pignatello and Xing 1996; Luthy et al. 1997). A significant amount of $\mathrm{CHCl}_{3}$ from sediment cores $\mathrm{T} 17$ ( $70 \%$ of the total mass) and $\mathrm{T} 18$ (61\% of the total mass) resisted desorption, indicating its presence as a resistant fraction. Sediment cores T17 and T18 contained small clay fractions ( 2 to $4 \%$, respectively). One possibility is that $\mathrm{CHCl}_{3}$ has been absorbed into elements of the mineral fraction of the sediments (e.g., the interlayer components of clays) over many years of interaction following abiotic formation from $\mathrm{CCl}_{4}$. This would be consistent with the resistive behavior of $\mathrm{CHCl}_{3}$ observed in these sediment cores and the similar behavior observed in the high clay content core from the Ringold Formation (T19). The difference in sediment sorption behavior of $\mathrm{CCl}_{4}$ versus $\mathrm{CHCl}_{3}$ may relate to the difference in their structure and the type of interaction that may occur with sediment (i.e., van der waals vs. hydrogen bonding).

The ease of extraction of residual $\mathrm{CHCl}_{3}$ with methanol suggests that $\mathrm{CHCl}_{3}$ is not permanently sequestered, and its release from sediment into migrating groundwater is controlled by multiple kinetic processes (e.g., diffusion out of meso- and micropores of sediment grains or from between clay layers, or out of organic matter coated on sediment grains). The degradation and sequestering properties of these sediments suggests that a certain portion of the $\mathrm{CHCl}_{3}$ in Hanford aquifer sediments is migrating quite slowly in groundwater. Also, the physical characteristics of the Ringold Formation mud unit (e.g., high silt and clay content) suggests that this unit is a good barrier to preventing $\mathrm{CCl}_{4}$ contamination of the upper confined aquifer.

The relatively few column experiments in this study showed a range of transport behavior that indicated the presence of both physical and chemical kinetic processes were at least partially controlling the release of solutes from the sediments. Tracer transport in two column experiments (T15, T18) exhibited equilibrium transport, but tracer transport in one column (T17) indicated the presence of mobile and immobile pore fluid. Simulation of the tracer breakthrough curve required the use of a two-region model, which describes diffusion between mobile and immobile pore fluid. Although tracer transport in the two other experiments (T15 and T18) was equilibrium-like, both carbon tetrachloride and chloroform desorption curves exhibited significant tailing greater than was caused by dispersion. Because there was no physical kinetic process (i.e., immobile/mobile pore fluid) apparent from tracer breakthrough, the slow release of these solutes from sediment surfaces was chemically controlled. Because simple organic compounds such as these should exhibit reversible partitioning to soil organic matter or mineral surfaces, this behavior could be indicative of an aging process resulting in stronger solute retention given the decades of contact time. Simulation of carbon tetrachloride and chloroform desorption was well approximated with a two-region kinetic model, and in some cases a first-order kinetic model, but were 
poorly fit with an equilibrium model. Simulation fits with the two kinetic models is indicative of the presence of one or more kinetic processes partially controlling the release of solutes from the sediment.

Recent site-wide modeling of the transport of $\mathrm{CCl}_{4}$ in aquifer sediment assumed advective transport $\left(\mathrm{K}_{\mathrm{d}}=0\right.$ and no degradation) and a continuous groundwater source for several case simulations (Bergeron and Cole 2004). Results indicated exceedence of compliance limits outside the Central Plateau waste management area and at the Columbia River during a 1,000-year period of simulation. Application of a best estimate $\mathrm{K}_{\mathrm{d}}$ value of $0.322 \mathrm{~L} / \mathrm{kg}$ and $\mathrm{CCl}_{4}$ half-life of $0.00956 \mathrm{y}^{-1}$ resulted in no exceedence of compliance limits at the same location after 1,000 years of simulation. From these results, the authors indicated how critical it is to have realistic values for these parameters for predicting the future movement of $\mathrm{CCl}_{4}$ from the 200 West Area. $\mathrm{CCl}_{4}$ and $\mathrm{CHCl}_{3}$ partition coefficients determined in this study are realistic in that they were obtained from Hanford sediments where $\mathrm{CCl}_{4}$ and $\mathrm{CHCl}_{3}$ had been in contact with the aquifer sediments for up to 30 years. The range in $\mathrm{CCl}_{4}$ partition coefficients in Hanford aquifer sediments from this study $(0.106 \mathrm{~L} / \mathrm{kg}$ to $0.367 \mathrm{~L} / \mathrm{kg})$ was lower by greater than a factor of ten as compared to the range estimated by Truex et al. (2001) of $0.016 \mathrm{~L} / \mathrm{kg}$ to $0.83 \mathrm{~L} / \mathrm{kg}$ based on $\mathrm{K}_{\mathrm{oc}}$. Use of this studies $\mathrm{K}_{\mathrm{d}}$ values in future simulations will result in more realistic predictions of $\mathrm{CCl}_{4}$ transport in Hanford groundwater with reduced uncertainty. The presence of significant concentrations of $\mathrm{CHCl}_{3}$ in the presence of lower-than-expected concentrations of $\mathrm{CCl}_{4}$ indicated $\mathrm{CCl}_{4}$ degradation in the sediment and the need to more accurately represent this process in transport modeling 


\subsection{References}

American Society of Agronomy (ASA). 1986a. "Hydrometer Method." Chapter 15-5 in Methods of Soil Analysis-Part 1, 2nd Edition of Physical and Mineralogical Methods, SSSA Book Series No. 5, ed. A Klute, pp. 404-408. Soil Science Society of America, Madison, Wisconsin.

American Society of Agronomy (ASA). 1986b. "Pynchnometer Method." Chapter 14-3 In Methods of Soil Analysis-Part 1, 2nd Edition of Physical and Mineralogical Methods, SSSA Book Series No. 5, ed. A Klute, pp. 378-379. Soil Science Society of America, Madison, Wisconsin.

American Society for Testing and Materials (ASTM) D4129-88. 1988. "Standard Test Method for Total and Organic Carbon in Water by High Temperature Oxidation and by Coulometric Detection." American Society for Testing and Materials, West Conshohocken, Pennsylvania.

American Society for Testing and Materials (ASTM) D2216-98. 1998. "Test Method for Laboratory Determination of Water (Moisture) Content of Soil and Rock." American Society for Testing and Materials, West Conshohocken, Pennsylvania.

Amonette J, D Workman, D Kennedy, J Fruchter, and Y Gorby. 2000. "Dechlorination of Carbon Tetrachloride by Fe(II) Associated with Goethite." Environmental Science and Technology 34(21):46064613.

Bauer RG and VJ Rohay. 2004. Data Quality Objectives Summary Report for Investigation of Dense, Non-Aqueous-Phase Liquid Carbon Tetrachloride in the 200 West Area. CP-15373, Rev. 0, Fluor Hanford, Richland, Washington.

Bergeron M.P and CR Cole. 2004. Recent Site-Wide Transport Modeling Related to the Carbon Tetrachloride Plume at the Hanford Site. PNNL-14855, Pacific Northwest National Laboratory, Richland, Washington.

DOE. 2001. Plutonium/Organic Rich Process Condensate/Process Waste Group Operable Unit RI/FS Work Plan: Includes the 200-PW-1, 200-PW-3, and 200-PW-6 Operable Units. DOE/RL-2001-01, Rev. 0 , Re-Issue. U.S. Department of Energy, Richland, Washington.

EPA. 2000. Test Methods for Evaluating Solid Waste, Physical/Chemical Methods (SW-846), Chapter 4, Organic Analytes, Table 4-1. U.S. Environmental Protection Agency, Washington, D.C.

Gleuckauf E. 1947. "Theory of Chromatography, Part II-V.” J. Chemistry Society, 36, 1302-1329.

Hartman MJ, LF Morasch, and WD Webber. 2002. Hanford Site Groundwater Monitoring for Fiscal Year 2001. PNNL-13788, Pacific Northwest National Laboratory, Richland, Washington.

Leehneer J and J Ahlrichs. 1971. "A Kinetic and Equilibrium Study of the Adsorption of Carbaryl and Parathion Upon Soil Organic Matter.” Soil Science Society of America Proceedings, 35,700-05. 
Luthy RG, GA Aiken, MI Brusseau, SD Cunningham, PM Gschwend, JJ Pignatello, M Reinhard, SJ Traina, WJ Weber, Jr, and JC Westall. 1997. "Sequestration of Hydrophobic Organic Contaminants by Geosorbents." Environmental Science and Technology 31:3341-3347.

Pignatello, JJ and B Xing. 1996. "Mechanisms of Slow Sorption of Organic Chemicals to Natural Particles." Environmental Science and Technology 30:1-11.

Serne RJ, BN Bjornstad, DG Horton, DC Lanigan, CW Lindenmeier, MJ Lindberg, RE Clayton, VL LeGore, KN Geiszler, SR Baum, MM Valenta, IV Kutnyakov, TS Vickerman, RD Orr, and CF Brown. 2004. Characterization of Vadose Zone Sediments Below the T Tank Farm: Boreholes C4104, C4105, 299-W10-196 and RCRA Borehole 299-W11-39. PNNL-14849, Pacific Northwest National Laboratory, Richland, Washington.

Toride N, FJ Leij, and MTh van Genuchten. 1993. "A Comprehensive Set of Analytical Solutions for Nonequilibrium Solute Transport with First-Order Decay and Zero-Order Production." Water Resources Research, 29, 2167-2182, 1993.

Toride N, FJ Leij, and MTh van Genuchten. 1999. The CXTFIT Code for Estimating Transport Parameters from Laboratory or Field Tracer Experiments. Research report No. 137, Version 2.1, U.S. Salinity Laboratory, Agricultural Research Service, U.S. Department of Agriculture, Riverside, California.

Truex MJ, CJ Murray, CR Cole, RJ Cameron, MD Johnson, RS Skeen, and CD Johnson. 2001. Assessment of Carbon Tetrachloride Groundwater Transport in Support of the Hanford Carbon Tetrachloride Innovative Technology Demonstration Program. PNNL-13560, Pacific Northwest National Laboratory, Richland, Washington.

van Genuchten M. and R Cleary. 1979. "Movement of Solutes in Soil; Computer Simulated and Laboratory Results in Soil Chemistry." In Physico-Chemical Models, pp 349-386, Elsevier Science, New York.

van Genuchten M, J Davidson, and P Wierenga. 1974. "An Evaluation of Kinetic and Equilibrium Equations for the Prediction of Pesticide Movement through Porous Media." Soil Science Society of America Proceedings 38:29-35.

Zhao X, MJ Szafranski, MA Maraqa, and TC Voice. 1999. "Sorption of Carbon Tetrachloride in a Low Organic Carbon Content Sandy Soil.” Environ. Tox. and Chem. 18:1755-1762. 
Appendix A

Calculation of Volatile Chlorinated Hydrocarbon Concentration from GC-MS Data 


\section{Appendix A}

\section{Calculation of Volatile Chlorinated Hydrocarbon Concentration from GC-MS Data}

Aqueous effluent samples (30 milliliters) from one dimensional column experiments were collected and analyzed in a way that minimized volatilization and sorptive losses of volatile chlorinated hydrocarbon in the samples. The columns and associated tubing were all of stainless steel (as opposed to plastic) to minimize sorptive losses. Effluent samples were collected in 125 or 154 milliliters glass bottles with 1-cm thick septa to minimize $\mathrm{CH}$ loss due to volatilization through the use of all stainless steel columns and tubing in the column system to eliminate diffusion (through plastics). The gas chromatograph (GC) - mass spectrometer (MS) analysis was conducted on the gas headspace (Section 3.1), and the original mass of the $\mathrm{CH}$ in the aqueous phase was calculated as described in the following paragraphs.

The equilibrium partitioning of compounds between aqueous and gas phases can be quantified using Henry's Law with dimensionless coefficients for carbon tetrachloride $\left(\mathrm{CCl}_{4} 1.0756\right)$, chloroform $\left(\mathrm{CHCl}_{3}\right.$ 0.157), trichloroethene (TCE 0.372), and pentaflurobenzene (PFB 0.341). The fraction of solute mass in the gas phase $(\mathrm{Fg})$ at equilibrium in a fixed volume container is calculated at $25^{\circ} \mathrm{C}$ from:

$$
\mathrm{Fg}=1 /\left[1+\left[\mathrm{Vaq} /\left[\mathrm{K}_{\mathrm{H}}-(\mathrm{Vtotal}-\mathrm{Vaq})\right]\right]\right]
$$

where $\mathrm{K}_{\mathrm{H}}=$ the dimensionless Henry's Law coefficient

$$
\begin{aligned}
& \text { Vtotal }=\text { the total volume of the vial }(125 \text { or } 154 \mathrm{~mL}) \\
& \text { Vaq }=\text { the aqueous sample volume }
\end{aligned}
$$

The calculated fraction of solute mass in the gas phase (Figure A.1) shows that for very small volumes of water (i.e., $<5$ milliliters in the 154 milliliters vial), $>98 \%$ of the organic mass is in the gas phase. With larger liquid volumes, the fraction in the gas phase is smaller. Carbon tetrachloride has the largest partition coefficient (i.e., is the most volatile), so a larger fraction remains in the gas phase relative to PFB, which is less volatile. 


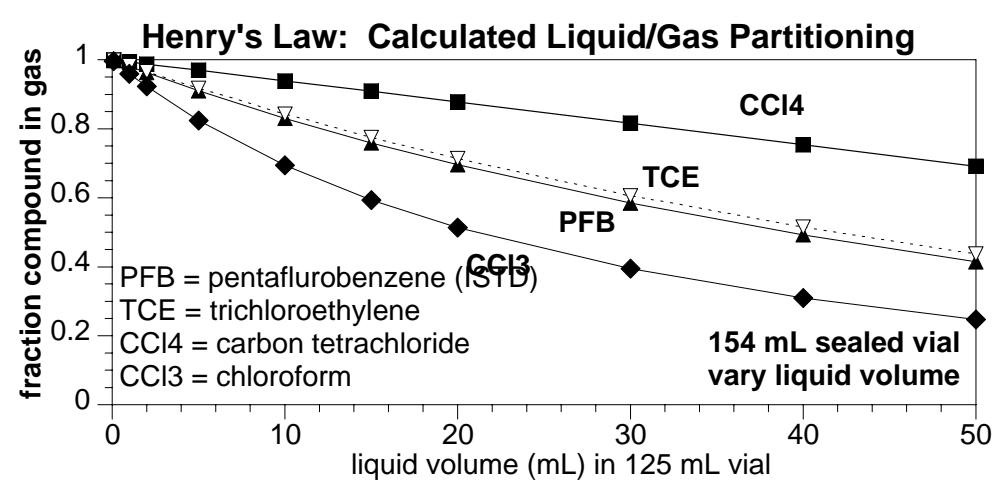

Figure A.1. Calculated Fraction Compound in Gas Phase in a Sealed Container of Limited Volume with Different Mass of Liquid Volume

Aqueous phase concentration (Caq) is calculated from gas phase concentration of $\mathrm{CH}$ using the following equation:

$$
\mathrm{Caq}=[\mathrm{Cgas} / 22.4][1 / \mathrm{Fg}][154-\mathrm{Vaq}] / \mathrm{Vaq}]
$$

Calculated values of the gas phase concentration given 1,000 ppb aqueous concentration (Figure A.2) illustrate three behaviors: 1) increasing the liquid volume results in increase gas phase concentration, 2 ) because the fraction of mass in the gas phase decreases with increasing volume, the sensitivity of the gas phase measurements is best at $<10$ milliliters liquid and lower at $>40$ milliliters, and 3) the internal standard PFB being less volatile, is even less sensitive at larger liquid volumes.

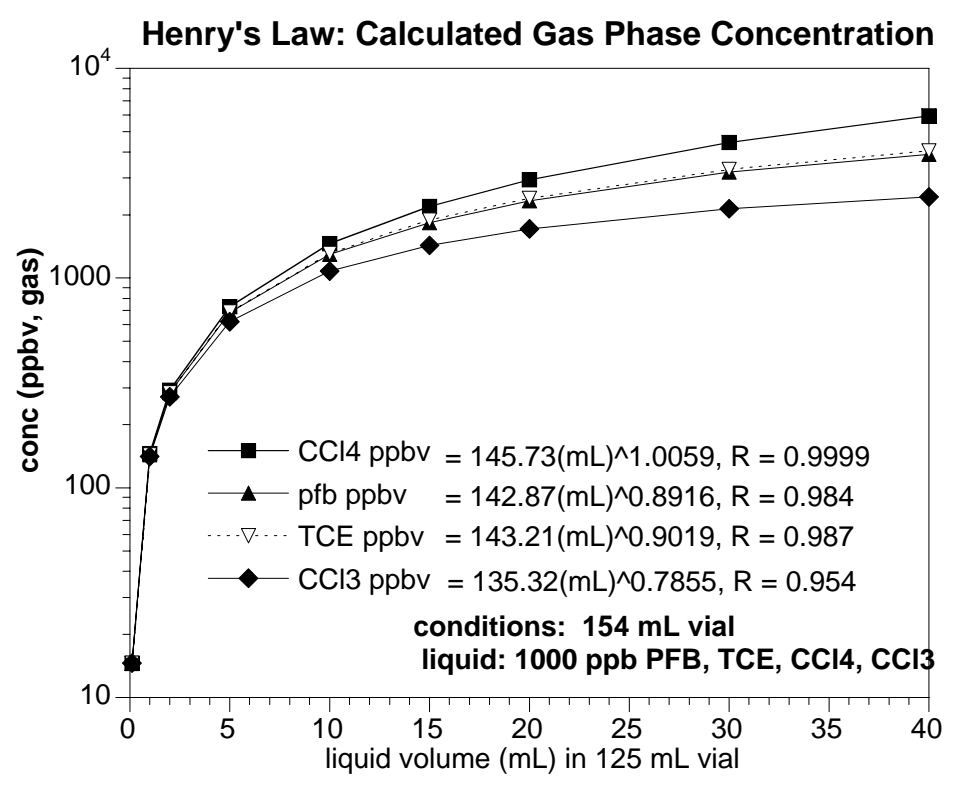

Figure A.2. Calculated Gas Phase Concentration for $\mathrm{CCl}_{4}, \mathrm{CCl}_{3}, \mathrm{TCE}$, and PFB with a Constant $1,000 \mathrm{ppb}$ in the Aqueous Phase 
If aqueous standards are made with the same liquid/gas volumes as the samples, then these Henry's Law calculations are not needed, as there is a direct comparison of gas phase area counts of a standard to a sample. Unfortunately the hydrocarbon liquid phase volumes of the effluent samples vary due to trapped air pockets in the sediment and inefficiencies associated with the column capping design. Standards made up at a specific liquid/gas ratio are not valid at a different liquid/gas ratio, as illustrated in Figure A.3, because the hydrocarbon partitioning between the liquid and gas phases is dependent on the relative liquid and gas volumes. For example a liquid phase concentration of $1,000 \mathrm{ppb}$ partitions $100 \%$ of the hydrocarbon mass into the gas phase with a liquid volume of 0.1 milliliters (and gas volume of 154 milliliters, but 30 milliliters aqueous samples would have an error of $20 \%$ for $\mathrm{CCl}_{4}$ and $40 \%$ for PFB.

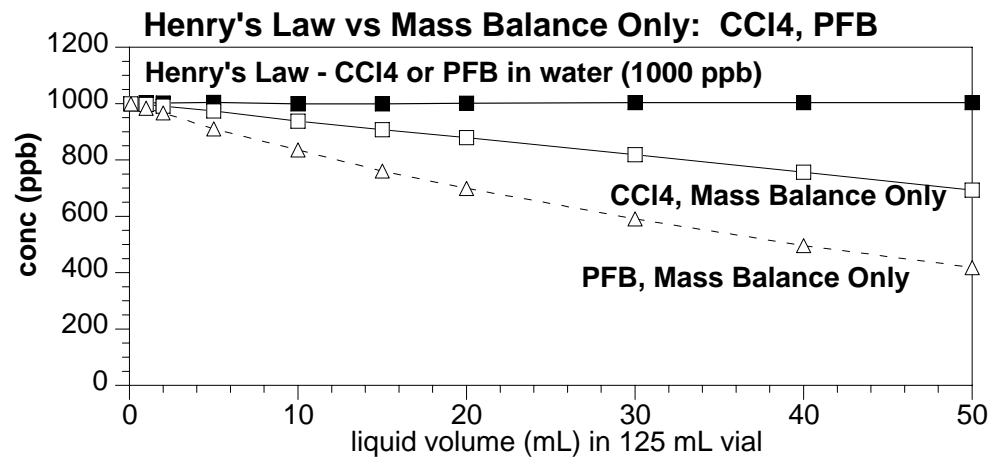

Figure A.3. Calculated Aqueous Concentration of $\mathrm{CCl}_{4}$ and PFB Using Mass Balance Only (i.e., assuming $100 \%$ liquid -> gas partitioning at all liquid/gas ratios)

In this study, the gas phase concentration of carbon tetrachloride (or TCE or $\mathrm{CHCl}_{3}$ ) was quantified by GC-MS as a ratio to the concentration of an internal standard, PFB, which is the most accurate approach for the analytical method. Unfortunately, because $\mathrm{PFB}$ and $\mathrm{CCl}_{4}$ have a difference in volatility, the percent of $\mathrm{CCl}_{4} / \mathrm{PFB}$ varies with the liquid/gas ratio, which means a slightly more complicated Henry's Law calculation is needed. To correct for this error, the ratio of $\mathrm{CCl}_{4} / \mathrm{PFB}$ or response factor (RF) was calculated at different liquid/gas ratios (Figure A.4) and compared with experimental data for two different data sets. The response factor increases with increasing liquid volume, because more $\mathrm{CCl}_{4}$ is in the vapor phase compared with PFB at higher liquid volumes (see Figure A.1). The response factor, in fact, is the ratio of the relative fractions in the gas phase shown in Figure A.1. 


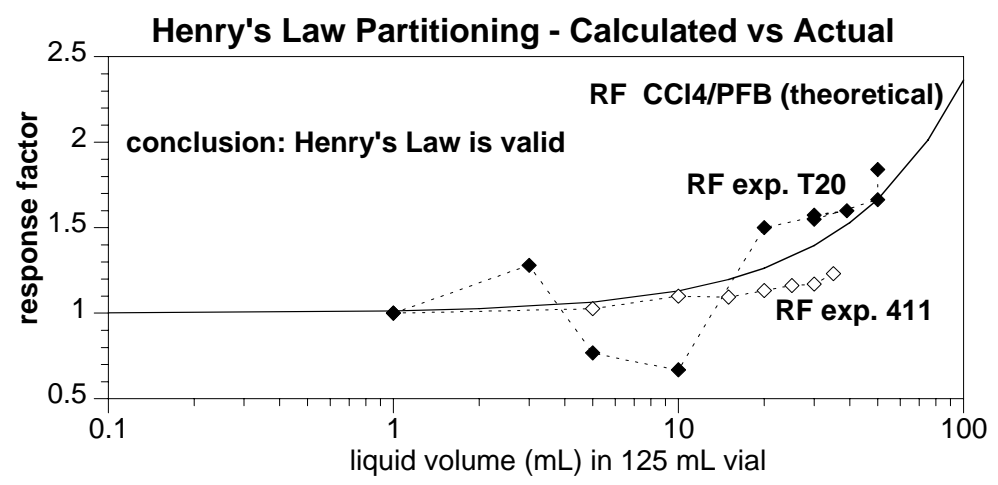

Figure A.4. Calculated and Actual Response Factor for $\mathrm{CCl}_{4}$

The response factors for $\mathrm{CCl}_{4}, \mathrm{TCE}$, and $\mathrm{CHCl}_{3}$ were calculated from Henry's $\mathrm{Law}$ (points, Figure A.5) and empirically fit (lines, Figure A.5) for use in correcting the GC-MS data for $\mathrm{CCl}_{4}, \mathrm{TCE}$, and $\mathrm{CHCl}_{3}$ collected using the internal standard PFB. In each case, the theoretical response factor was adjusted to a value of 1.00 at 30 milliliters, since standards were made at 30 milliliters. The consequence of this variable response factor is that for sample volumes other than 30 milliliters, the concentration is adjusted. For $\mathrm{CCl}_{4}$, the response factor is greater for larger volumes (Figure A.5a) because $\mathrm{CCl}_{4}$ is more volatile than PFB (Figure A.1). For TCE, the response factor essentially does not vary with liquid/gas ratio (Figure A.5b) because PFB and TCE have nearly the same Henry's Law partition coefficient (Figure A2). For $\mathrm{CHCl}_{3}$, the response factor is smaller for larger volumes (Figure A.5c) because $\mathrm{CHCl}_{3}$ is less volatile than PFB (Figure A.1).

Given the variable response factors, experiment aqueous phase concentrations can be calculated from: a) the gas phase concentration (i.e., Figure A.2), and b) the aqueous concentration using the internal standard (PFB; aka, Figure A.5a). A comparative study illustrates that both techniques correctly account for gas/liquid partitioning. In this test, a solution of $107 \mathrm{ppb} \mathrm{CCl}_{4}$ was placed in 154 milliliters vials with different volumes ranging from 1 to 50 milliliters. The uncorrected aqueous phase $\mathrm{CCl}_{4}$ concentration (Figure A.6, open diamonds) vary above and below $107 \mathrm{ppb}$ in a systematic fashion (average $99.5 \pm 16.9$, with trend). When the variable response factor (Figure A.5a) is applied to this data, most vials are near the calculated concentration of $107 \mathrm{ppb}$ (average 108.3 \pm 4.53 , with the exception of the 1 milliliters point. In comparison, using single ion monitoring at $168 \mathrm{amu}$ (i.e., area counts), most vials are also near the calculated concentration (average $107.5 \pm 3.29$ ), again with the exception of the 1 milliliters point. Therefore, either method correctly accounts for the liquid/gas partitioning at differing volumes, with a slightly tighter distribution for the single ion monitoring data. 

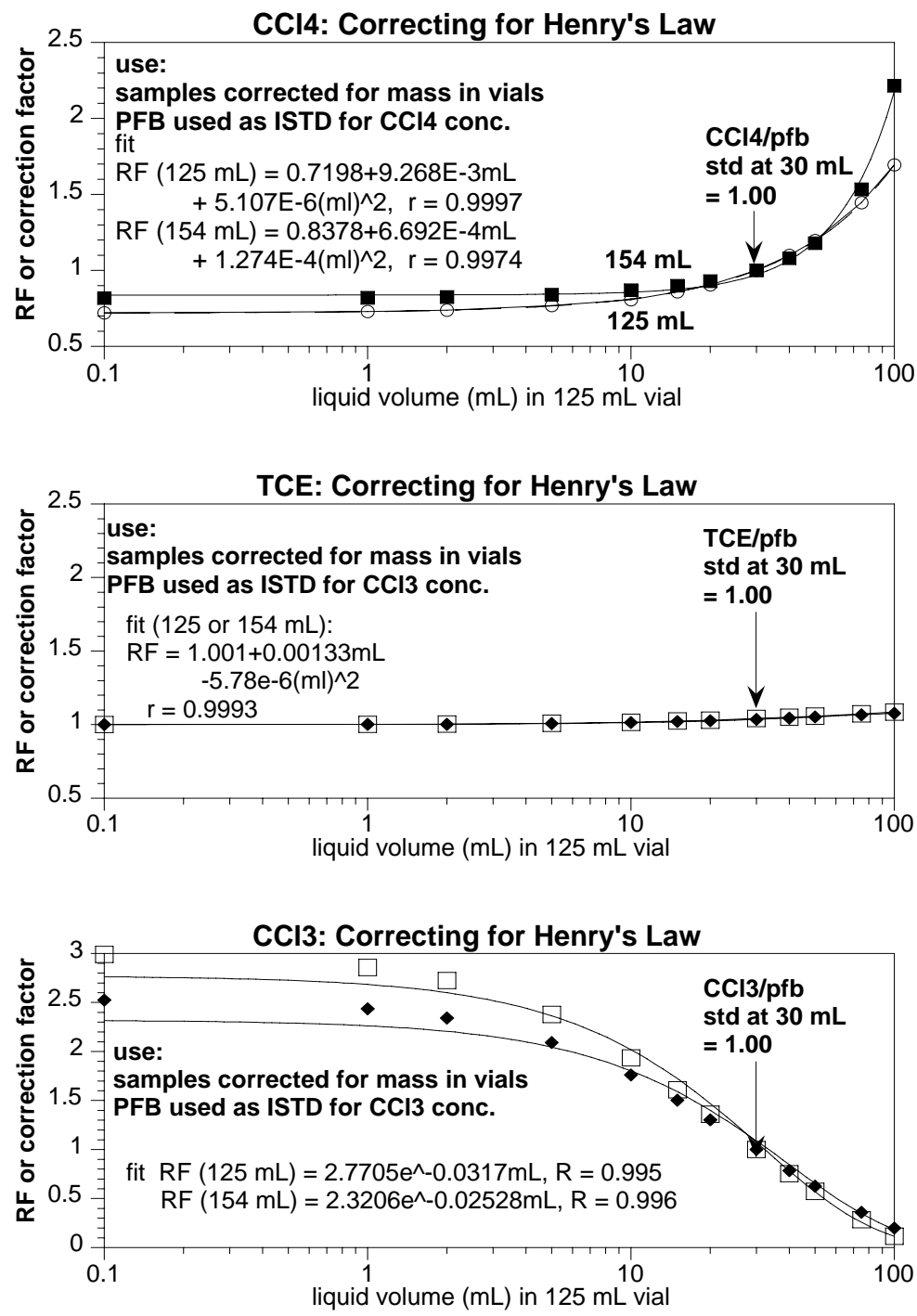

Figure A.5. Response Factors for $\mathrm{CCl}_{4}, \mathrm{TCE}$, and $\mathrm{CCl}_{3}$ as a Function of the Aqueous Sample Volume in a 154 Milliliters Vial 


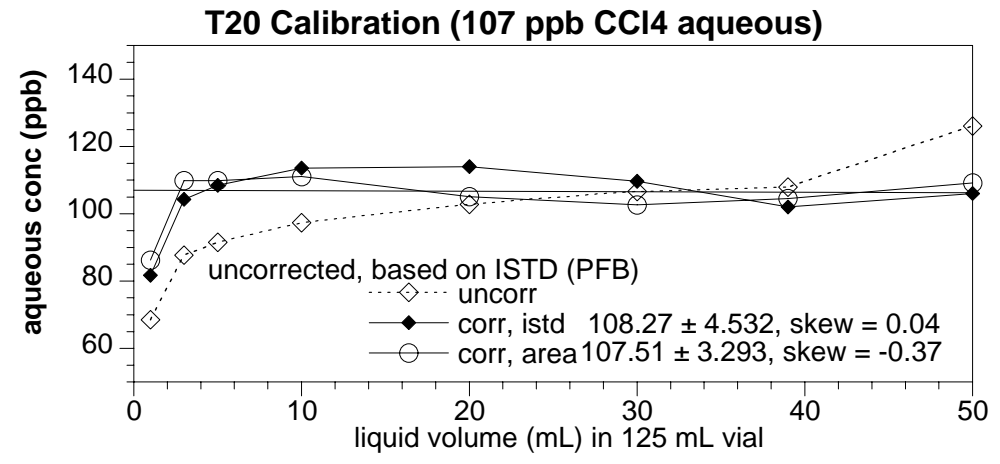

Figure A.6. Comparison of Techniques for Correction of Gas/Liquid Partitioning at Different Liquid Volumes in Sealed Vials 


\section{Appendix B}

Column Experiment Breakthrough Data 


\section{Appendix B}

\section{Column Experiment Breakthrough Data}

T15, 231-231.5' borehole C3426

\begin{tabular}{|c|c|c|c|c|c|c|}
\hline \# & $\begin{array}{l}\text { time } \\
\text { (h) }\end{array}$ & $\begin{array}{l}\text { pore } \\
\text { vol. }\end{array}$ & $\begin{array}{c}\mathrm{CCl} 4 \mathrm{aq} \\
(\mathrm{ppb})\end{array}$ & $\begin{array}{l}\mathrm{CCl} 4^{*} \\
(\mathrm{C} / \mathrm{Co})\end{array}$ & $\begin{array}{c}\text { EC pore } \\
\text { vol. }\end{array}$ & $\begin{array}{c}E C \\
(\mathrm{C} / \mathrm{Co}) \\
\end{array}$ \\
\hline $\mathrm{T} 15.1$ & 0.0 & 0.000 & & & 0.000 & 1.000 \\
\hline T15.2 & 10.5 & 0.599 & 2.800 & 0.074 & 0.300 & 1.000 \\
\hline T15.3 & 11.8 & 0.692 & 7.325 & 0.194 & 0.600 & 1.000 \\
\hline T15.4 & 13.0 & 0.785 & 16.84 & 0.447 & 0.6052 & 1.006 \\
\hline T15.5 & 14.3 & 0.878 & 29.76 & 0.789 & 0.73162 & 1.000 \\
\hline T15.6 & 15.5 & 0.971 & 33.39 & 0.886 & 0.74649 & 0.955 \\
\hline T15.7 & 16.8 & 1.064 & 37.70 & 1.000 & 0.75393 & 0.909 \\
\hline T15.8 & 18.0 & 1.157 & 28.89 & 0.766 & 0.76136 & 0.864 \\
\hline T15.9 & 19.3 & 1.250 & 25.34 & 0.672 & 0.78367 & 0.803 \\
\hline T15.10 & 20.5 & 1.343 & 19.64 & 0.521 & 0.82086 & 0.758 \\
\hline T15.11 & 21.8 & 1.436 & 15.04 & 0.399 & 0.8506 & 0.697 \\
\hline T15.12 & 23.0 & 1.529 & 11.58 & 0.307 & 0.87291 & 0.652 \\
\hline T15.13 & 24.3 & 1.622 & 11.76 & 0.312 & 0.89522 & 0.591 \\
\hline T15.14 & 25.5 & 1.715 & 8.394 & 0.223 & 0.92497 & 0.545 \\
\hline T15.15 & 26.8 & 1.808 & 6.331 & 0.168 & 0.94728 & 0.515 \\
\hline T15.16 & 31.8 & 2.180 & 5.294 & 0.140 & 0.97703 & 0.455 \\
\hline T15.17 & 36.8 & 2.552 & 4.388 & 0.116 & 1.0068 & 0.409 \\
\hline T15.18 & 41.8 & 2.923 & 3.745 & 0.099 & 1.0514 & 0.348 \\
\hline T15.19 & 46.8 & 3.295 & 2.952 & 0.078 & 1.0811 & 0.303 \\
\hline T15.20 & 51.8 & 3.667 & 1.068 & 0.028 & 1.1332 & 0.242 \\
\hline T15.21 & 56.8 & 4.039 & 1.944 & 0.052 & $\begin{array}{l}1.1 / 18 \\
1.2447\end{array}$ & $\begin{array}{l}0.182 \\
0.152\end{array}$ \\
\hline T15.22 & 96.8 & 7.014 & 0.000 & 0.000 & $\begin{array}{l}1.2441 \\
1.2819\end{array}$ & 0.132 \\
\hline T15.23 & 136.8 & 9.988 & 0.000 & 0.000 & 1.3712 & 0.076 \\
\hline T15.24 & 176.8 & 12.963 & 0.000 & 0.000 & 1.4455 & 0.061 \\
\hline T15.25 & 216.8 & 15.937 & & & 1.4753 & 0.0303 \\
\hline \multirow{2}{*}{\multicolumn{5}{|c|}{${ }^{*} \mathrm{Co}=37.7 \mathrm{ppb}$}} & 1.5496 & 0.01515 \\
\hline & & & & & 1.7356 & 0.01515 \\
\hline
\end{tabular}

B. 1 
T17, 293-293.5' borehole C3426

\begin{tabular}{|c|c|c|c|c|c|c|c|c|c|c|}
\hline \# & $\begin{array}{l}\text { time } \\
\text { (h) }\end{array}$ & $\begin{array}{l}\text { pore } \\
\text { vol. }\end{array}$ & $\begin{array}{c}\mathrm{CCl} 4 \mathrm{aq} \\
(\mathrm{ppb})\end{array}$ & $\begin{array}{l}\mathrm{CCl} 4^{*} \\
(\mathrm{C} / \mathrm{Co})\end{array}$ & $\begin{array}{c}\mathrm{CCl} 3 \mathrm{aq} \\
(\mathrm{ppb})\end{array}$ & $\begin{array}{l}\mathrm{CCl} 3 * * \\
(\mathrm{C} / \mathrm{Co})\end{array}$ & $\begin{array}{c}\text { TCE aq } \\
(\mathrm{ppb})\end{array}$ & $\begin{array}{l}\text { TCE** } \\
\text { (C/Co) }\end{array}$ & $\begin{array}{c}\text { EC pore } \\
\text { vol. }\end{array}$ & $\begin{array}{c}E C \\
(\mathrm{C} / \mathrm{Co})\end{array}$ \\
\hline T17.1 & 5.25 & 0.452 & 10.38 & 0.130 & 41.01 & 0.984 & 1.28 & 0.160 & 0.000 & 1.000 \\
\hline T17.2 & 10.5 & 1.056 & 34.96 & 0.437 & 41.66 & 1.000 & 0.00 & & 0.200 & 1.000 \\
\hline T17.3 & 11.8 & 1.181 & 55.09 & 0.688 & 40.52 & 0.973 & 0.00 & & 0.400 & 1.000 \\
\hline T17.4 & 13.0 & 1.307 & 68.77 & 0.859 & 40.37 & 0.969 & 0.00 & & 0.451 & 0.993 \\
\hline T17.5 & 14.3 & 1.433 & 63.28 & 0.791 & 33.21 & 0.797 & 0.00 & & 0.471 & 0.977 \\
\hline T17.6 & 15.5 & 1.558 & 80.04 & 1.000 & 40.60 & 0.975 & 0.00 & & 0.481 & 0.955 \\
\hline T17.7 & 16.8 & 1.684 & 59.37 & 0.742 & 30.76 & 0.738 & 0.00 & & 0.491 & 0.927 \\
\hline T17.8 & 18.0 & 1.810 & 52.97 & 0.662 & 32.48 & 0.780 & 0.00 & & 0.511 & 0.861 \\
\hline T17.9 & 19.3 & 1.935 & 53.27 & 0.665 & 29.36 & 0.705 & 0.00 & & 0.522 & 0.783 \\
\hline T17.10 & 20.5 & 2.061 & 8.99 & 0.112 & 58.95 & 1.415 & 1.28 & 0.160 & 0.542 & 0.706 \\
\hline T17.11 & 21.8 & 2.186 & 38.94 & 0.486 & 32.18 & 0.772 & 1.92 & 0.240 & 0.572 & 0.645 \\
\hline T17.12 & 23.0 & 2.312 & 43.33 & 0.541 & 17.98 & 0.432 & 3.34 & 0.418 & 0.592 & 0.585 \\
\hline T17.13 & 24.3 & 2.438 & 36.07 & 0.451 & 23.02 & 0.553 & 1.03 & 0.129 & 0.622 & 0.524 \\
\hline T17.14 & 25.5 & 2.563 & 36.31 & 0.454 & 21.01 & 0.504 & 2.66 & 0.333 & 0.702 & 0.441 \\
\hline T17.15 & 26.8 & 2.689 & 36.28 & 0.453 & 23.97 & 0.575 & 1.19 & 0.149 & 0.823 & 0.386 \\
\hline T17.16 & 31.8 & 3.191 & 29.41 & 0.367 & 18.35 & 0.440 & 1.60 & 0.200 & 0.903 & 0.325 \\
\hline T17.17 & 36.8 & 3.694 & & & & & & & 1.034 & 0.286 \\
\hline T17.18 & 41.8 & 4.196 & 10.26 & 0.128 & 28.17 & 0.676 & 0.95 & 0.119 & 1.235 & 0.236 \\
\hline T17.19 & 46.8 & 4.699 & 4.43 & 0.055 & 6.098 & 0.146 & 0.83 & 0.104 & 1.436 & 0.170 \\
\hline T17.20 & 51.8 & 5.202 & 7.99 & 0.100 & 5.604 & 0.135 & 1.72 & 0.215 & 1.919 & 0.137 \\
\hline T17.21 & 56.8 & 5.704 & 6.32 & 0.079 & 4.350 & 0.104 & 0.63 & 0.079 & 2.089 & 0.093 \\
\hline T17.22 & 96.8 & 9.724 & 6.32 & 0.079 & 4.027 & 0.097 & 0.58 & 0.073 & 2.240 & 0.061 \\
\hline T17.23 & 136.8 & 13.74 & 1.85 & 0.023 & 0.856 & 0.021 & 0.66 & 0.083 & 2.501 & 0.038 \\
\hline T17.24 & 176.8 & 17.76 & 0.72 & 0.009 & 0.475 & 0.011 & 0.58 & 0.073 & 2.994 & 0.023 \\
\hline T17.25 & 216.8 & 21.78 & 1.00 & 0.012 & 0.757 & 0.018 & 0.90 & 0.113 & 4.109 & 0.013 \\
\hline
\end{tabular}


T18, 366-366.5' borehole C3426

\begin{tabular}{|c|c|c|c|c|c|c|c|c|c|c|}
\hline \# & $\begin{array}{l}\text { time } \\
\text { (h) }\end{array}$ & $\begin{array}{l}\text { pore } \\
\text { vol. }\end{array}$ & $\begin{array}{c}\mathrm{CCl} 4 \mathrm{aq} \\
(\mathrm{ppb})\end{array}$ & $\begin{array}{l}\mathrm{CCl} 4^{*} \\
\text { (C/Co) }\end{array}$ & $\begin{array}{c}\mathrm{CCl} 3 \mathrm{aq} \\
(\mathrm{ppb})\end{array}$ & $\begin{array}{l}\mathrm{CCl} 3 * * \\
(\mathrm{C} / \mathrm{Co})\end{array}$ & $\begin{array}{l}\text { TCE aq } \\
\text { (ppb) }\end{array}$ & $\begin{array}{l}\text { TCE** } \\
\text { (C/Co) }\end{array}$ & $\begin{array}{c}\text { EC pore } \\
\text { vol. }\end{array}$ & $\begin{array}{c}E C \\
(\mathrm{C} / \mathrm{Co})\end{array}$ \\
\hline T18.0 & 4.50 & 0.452 & 141.30 & 0.252 & 1.17 & 0.030 & 2.80 & & 0.000 & 1.000 \\
\hline T18.1 & 9.05 & 0.910 & 566.56 & 1.012 & 39.65 & 1.000 & 1.28 & & 0.333 & 1.000 \\
\hline T18.2 & 10.5 & 1.056 & 407.96 & 0.729 & 15.03 & 0.379 & 0.00 & & 0.697 & 1.000 \\
\hline T18.3 & 11.8 & 1.181 & 479.28 & 0.856 & 14.09 & 0.355 & 0.00 & & 0.707 & 0.978 \\
\hline T18.4 & 13.0 & 1.307 & 499.96 & 0.893 & 12.44 & 0.314 & 0.00 & & 0.737 & 0.936 \\
\hline T18.5 & 14.3 & 1.433 & 441.90 & 0.789 & 10.32 & 0.260 & 0.00 & & 0.757 & 0.865 \\
\hline T18.6 & 15.5 & 1.558 & 376.96 & 0.673 & 15.86 & 0.400 & 0.00 & & 0.787 & 0.811 \\
\hline T18.7 & 16.8 & 1.684 & 288.33 & 0.515 & 10.79 & 0.272 & 0.00 & & 0.818 & 0.757 \\
\hline T18.8 & 18.0 & 1.810 & 218.40 & 0.390 & 8.11 & 0.205 & 0.00 & & 0.848 & 0.691 \\
\hline T18.9 & 19.3 & 1.935 & 221.39 & 0.395 & 7.42 & 0.187 & 0.00 & & 0.888 & 0.645 \\
\hline T18.10 & 20.5 & 2.061 & 136.10 & 0.243 & 4.56 & 0.115 & 1.28 & & 0.928 & 0.598 \\
\hline T18.11 & 21.8 & 2.186 & 117.76 & 0.210 & 4.24 & 0.107 & 1.92 & & 1.019 & 0.544 \\
\hline T18.12 & 23.0 & 2.312 & 101.28 & 0.181 & 4.24 & 0.107 & 3.34 & & 1.059 & 0.475 \\
\hline T18.13 & 24.3 & 2.438 & 88.368 & 0.158 & 3.83 & 0.097 & 1.03 & & 1.129 & 0.414 \\
\hline T18.14 & 25.5 & 2.563 & 69.773 & 0.125 & 3.36 & 0.085 & 2.66 & & 1.190 & 0.350 \\
\hline T18.15 & 26.8 & 2.689 & 55.581 & 0.099 & 2.70 & 0.068 & 1.19 & & 1.240 & 0.304 \\
\hline T18.16 & 31.8 & 3.191 & 40.259 & 0.072 & 2.35 & 0.059 & 1.60 & & 1.290 & 0.252 \\
\hline T18.17 & 36.8 & 3.694 & & & & & & & 1.380 & 0.191 \\
\hline T18.18 & 41.8 & 4.196 & 27.314 & 0.049 & 2.16 & 0.054 & 0.95 & & 1.481 & 0.147 \\
\hline T18.19 & 46.8 & 4.699 & 13.700 & 0.024 & 1.230 & 0.031 & 0.83 & & 1.662 & 0.100 \\
\hline T18.20 & 51.8 & 5.202 & 11.395 & 0.020 & 1.010 & 0.025 & 1.72 & & 1.863 & 0.069 \\
\hline T18.21 & 56.8 & 5.704 & 8.226 & 0.015 & 0.776 & 0.020 & 0.63 & & 2.054 & 0.047 \\
\hline T18.22 & 96.8 & 9.724 & 2.506 & 0.004 & 0.226 & 0.006 & 0.58 & & 2.225 & 0.029 \\
\hline T18.23 & 136.8 & 13.74 & 1.300 & 0.002 & 0.122 & 0.003 & 0.66 & & 2.436 & 0.015 \\
\hline T18.24 & 176.8 & 17.76 & 1.785 & 0.003 & 0.379 & 0.010 & 0.58 & & 2.818 & 0.002 \\
\hline
\end{tabular}


T19, 421.5-422' borehole C3426

\begin{tabular}{|c|c|c|c|c|c|c|c|c|}
\hline \# & $\begin{array}{l}\text { time } \\
\text { (h) }\end{array}$ & $\begin{array}{l}\text { pore } \\
\text { vol. }\end{array}$ & $\begin{array}{c}\mathrm{CCl} 4 \mathrm{aq} \\
(\mathrm{ppb})\end{array}$ & $\begin{array}{l}\mathrm{CCl} 4^{*} \\
(\mathrm{C} / \mathrm{Co})\end{array}$ & $\begin{array}{c}\mathrm{CCl} 3 \mathrm{aq} \\
(\mathrm{ppb})\end{array}$ & $\begin{array}{l}\mathrm{CCl} 3 * * \\
(\mathrm{C} / \mathrm{Co})\end{array}$ & $\begin{array}{c}\text { TCE aq } \\
(p p b)\end{array}$ & $\begin{array}{l}\text { TCE** } \\
\text { (C/Co) }\end{array}$ \\
\hline T18.1 & 9.05 & 0.910 & 0.00 & & 0.00 & & 0.00 & \\
\hline T18.2 & 10.5 & 1.056 & 0.00 & & 0.00 & & 0.00 & \\
\hline T18.3 & 11.8 & 1.181 & 0.00 & & 0.00 & & 0.00 & \\
\hline T18.4 & 13.0 & 1.307 & 0.00 & & 0.00 & & 0.00 & \\
\hline T18.5 & 14.3 & 1.433 & 0.00 & & 0.00 & & 0.00 & \\
\hline T18.6 & 15.5 & 1.558 & & & & & & \\
\hline T18.7 & 16.8 & 1.684 & & & & & & \\
\hline T18.8 & 18.0 & 1.810 & & & & & & \\
\hline T18.9 & 19.3 & 1.935 & 0.00 & & 0.00 & & 0.00 & \\
\hline T18.10 & 20.5 & 2.061 & & & & & & \\
\hline T18.11 & 21.8 & 2.186 & & & & & & \\
\hline T18.12 & 23.0 & 2.312 & & & & & & \\
\hline T18.13 & 24.3 & 2.438 & & & & & & \\
\hline T18.14 & 25.5 & 2.563 & & & & & & \\
\hline T18.15 & 26.8 & 2.689 & 0.000 & & 0.000 & & 0.000 & \\
\hline T18.16 & 31.8 & 3.191 & & & & & & \\
\hline T18.17 & 36.8 & 3.694 & & & & & & \\
\hline T18.18 & 41.8 & 4.196 & & & & & & \\
\hline T18.19 & 46.8 & 4.699 & 0.000 & & 0.000 & & 0.000 & \\
\hline T18.20 & 51.8 & 5.202 & & & & & & \\
\hline T18.21 & 56.8 & 5.704 & & & & & & \\
\hline T18.22 & 96.8 & 9.724 & 0.000 & & 0.000 & & 0.000 & \\
\hline T18.23 & 136.8 & 13.74 & & & & & & \\
\hline T18.24 & 176.8 & 17.76 & & & & & & \\
\hline
\end{tabular}

B. 4 
PNNL-15239

\section{Distribution}

No. of

Copies

\section{OFFSITE}

Wes Bratton

Vista Engineering Technologies, L.L.C. 8203 W. Quinault, Bldg. C, Suite 200

Kennewick, WA 99336

\section{U.S. Geological Survey}

R. S. Dinicola

Washington Water Science Center 1210 Pacific Ave., Suite 600

Tacoma, WA 98402

\section{ONSITE}

\section{DOE Richland Operations Office}

B. L. Charboneau

B. L. Foley

J. G. Morse

K. M. Thompson

A. C. Tortoso

10 Fluor Hanford, Inc.

J. V. Borghese

E6-35

M. E. Byrnes

E6-35

D. B. Erb

T. W. Fogwell

B. H. Ford

P. M. Gent

S. W. Petersen

V. J. Rohay

L. C. Swanson

M. E. Todd-Robertson
No. of

Copies

U.S. Environmental Protection Agency

D. E. Faulk

T4-04

Washington State Department of Ecology

D. Goswami

H0-57

29 Pacific Northwest National Laboratory

J. E. Amonette K8-96

M. Bergeron K9-36

C. F. Brown P7-22

R. W. Bryce E6-35

M. D. Freshley K9-33

C. T. Kincaid K9-33

G. V. Last K6-81

A. V. Mitroshkov K6-96

M. Oostrom K9-33

D. R. Rector K7-15

R. G. Riley (10) K6-96

M. L. Rockhold K9-36

R. J. Serne K9-36

D. S. Sklarew K9-96

J. E. Szecsody K3-61

C. J. Thompson K6-96

P. D. Thorne K9-33

M. J. Truex K6-96

Hanford Technical Library (2) P8-55 